\title{
Space Syntax Applied in Urban Practice
}

\section{Contents}

7.1 From Theory to Practice-The "What Happens if..." Relationship ........................................ 214

7.2 Spatial Principles for Designing Vital and Safe Public Realms............................................. 215

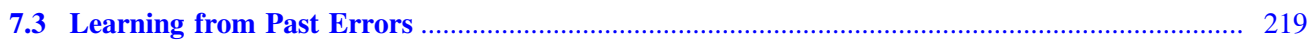

7.4 Examples from Practice ....................................................................................................... 222

7.4.1 Public Realm Design for Trafalgar Square, London, United Kingdom .................................. 222

7.4.2 Evaluating a New Road Connection Through the City of Leiden,

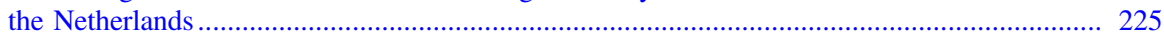

7.4.3 The Densification Strategy Plan for Bergen Municipality in Norway ................................... 227

7.4.4 Regional Strategic Plan for North Holland, the Netherlands ................................................ 229

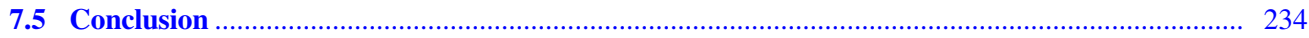

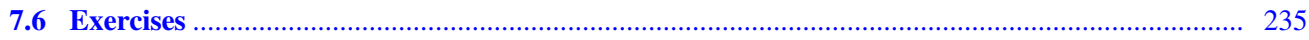

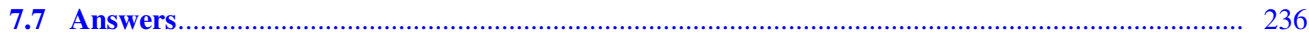

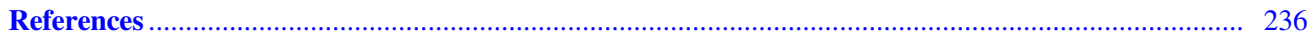

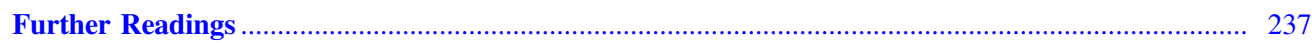

\section{Abstract}

In this chapter, we discuss the application of space syntax in consultancy for urban planning design and practice. First, we present the scientific challenges to tying general understandings and theories to urban planning and design practice. Some elementary principles for communicating results from research and theories to practitioners are demonstrated. We further explain the principles for successful master planning and the principles for designing vital and safe public realms related to the use of space syntax. This is followed by a discussion on how to avoid common errors when planning for vital neighbourhoods and cities. We present examples from practice where space syntax has played a major role. These include regenerating Trafalgar Square in London, evaluating various proposals for a new road link in the Dutch city of Leiden, developing strategies for the whole province of North Holland, and densification strategies in the Norwegian town of Bergen. In the conclusion, we discuss major pitfalls when applying space syntax to urban design and planning projects in practice. Exercises are provided at the end of the chapter.

\section{Keywords}

Urban planning and design practice $\bullet$ Option testing $\bullet$ Baseline studies $\bullet$ Vital and safe neighbourhoods and cities

\section{Key Concepts}

Urban design consultancy $\bullet$ Baseline studies $\bullet$ Principles for vital and safe public realm design $\bullet$ Scenario and option testing 


\section{Learning Objectives}

After studying this chapter you will

- have knowledge about how to connect space syntax theory and methods to urban planning and design practice;

- have an understanding of how space syntax is applied in urban planning and design practice;

- be familiar with the principles for designing vital and safe public realms, and

- be able to carry out an urban diagnosis and prognosis approach with scenario and option testing.

\subsection{From Theory to Practice-The "What Happens if..." Relationship}

How we apply space syntax in practice is based on results from established theories and research. The application of the space syntax method does not necessarily reveal the 'right' design solution or optimal answer to spatial challenges, but it can to some extent predict the socio-economic impacts of urban planning and design proposals. The theory of spatial combinatorics, the theory of natural movement (economic process), and the theory of the natural urban transformation process give (Ye and van Nes 2014) indications on how an urban design might function after implementation. Hence, the space syntax method can provide detailed analyses of the spatial configurative changes the design proposal will bring about (Yamu et al. 2021). However, drawing final conclusions on the indications of the socio-economic effects is heavily dependent on a variety of conditions. First of all, baseline analyses of the current context must be made. The interpretations of the analyses depend on existing space syntax theories and on research results related to the problems that need to be solved. Second, you have to be aware of the limitations of space syntax, for example, issues related to social rationality, place identity, and various cultural contexts cannot be addressed through space syntax.

Space syntax is not capable of making normative statements about what the optimal design solution is. Instead, the primary aim of space syntax is to find out what is desired to be achieved and what actually can be achieved with the urban design proposal. Once a variety of spatial options have been tested with space syntax, possible effects - in connection with current theories on space and spatial relationships and on space in relation to movement and economic developments-can be derived (Yamu et al. 2021). Thus, it all depends on the following question: "What happens if ..."

If I do this, the effect will be that.

If I want this, I had better do that.

With regard to context-dependent situations, where insights into local culture, laws, and regulations are important, we are dealing with the following types of statements:

If I want to do this, I have to gain knowledge on the local culture, setting, users' intentions, and decision-makers' intentions first

If I want to do this, I have to understand that the particular local context might block the intended and wanted effects.

To create a well-functioning built environment, space has to be dealt with before the form. This means that the planning and design of urban areas have to deal with the pathway network first (Seamon 1994, p. 36). If people's movement through the urban street network generates land use patterns correlating with various spatial integration values, urban design proposals can be tested to get an indication of the potential degree of (vital) urban street life. If the land use intensity is affected by the volume and density of people in the streets, then space syntax analysis allows one to assess effects for the future potential for street life connected to land use. If the spatial conditions are assessed, then the design of the built form can be carried out. Space syntax can help urban planners and designers in their decision-making for well-functioning urban designs because it reveals the hidden spatial structures of various design proposals for the same area (Karimi 2012).

However, the space syntax jargon can often be difficult to use in communication with urban planners and designers. The challenge is to create a consistent and understandable space syntax language that allows for easy communication with practitioners and space syntax novices from urban planning and design and other disciplines. Thus, a simple visual and diagrammatic language is often key for the successful communication of space syntax results. Space syntax results have to be understandable, for example, by road engineers, urban planners, urban designers, architects, criminologists, decision-makers, and project developers. As a support tool in communication, the question 'What happens if...' is often very helpful. It can also be formulated as 'If we do this, the effect will be that.' This can be applied to the master planning principles, as well as to the safe public realm principles. Applying space syntax to urban planning and design scenarios to answer the 'What happens if...' question is referred to in the space syntax jargon as 'option testing'. 


\subsection{Spatial Principles for Designing Vital and Safe Public Realms}

In the following, we introduce nine spatial principles for designing vital and safe public realms. These principles include recommendations from a city and neighbourhood scale to a micro-scale. For these principles, the 'What happens if...' relationship also applies. However, the presented principles are limited in their methodological setup, and this non-exhaustive 'checklist' only seeks to provide a guideline for creating safe, lively, and economically vibrant neighbourhoods. The principles are based on the following observations from research and practice (Van Nes and López 2010, 2013). Neighbourhoods with a relatively high crime rate compared to neighbourhoods with a low crime rate generally have their main routes running through their local centres. A well-integrated and well-connected main road encourages a diverse micro-economy, and it supports a natural surveillance mechanism due to a mix of different types of people. Furthermore, the position of buildings and the locations of windows and entrances, including active functions on the ground floor level, can create safer and more vital neighbourhoods with a higher degree of social control.

Let us not forget that the social composition of residents, their lifestyles, and their decisions are important factors in ranking the priorities for spatial improvements in neighbourhoods. Spatial parameters matter in the socio-economic performance of a neighbourhood. It is all about how the spatial layout contributes to reducing criminal opportunities, shaping a natural social control mechanism, and shaping opportunities for social interactions and a flourishing micro-economy. The nine principles for creating a vital and safe public realm are as follows:

\section{(1) Main routes passing through neighbourhoods}

Main routes have to go through neighbourhoods instead of around neighbourhoods. This assures that visitors travel through the neighbourhood and thus become potential customers to the neighbourhood's micro-economic market of local businesses. Further, visitors add to the natural surveillance mechanism of the neighbourhood due to their presence. The variety of different types of people in the streets throughout the day creates a safer neighbourhood, but social safety is often sacrificed in favour of traffic safety. If main routes are planned and implemented to go around a neighbourhood, the effect will most likely be segregated and mono-functional neighbourhoods (Fig. 7.1).
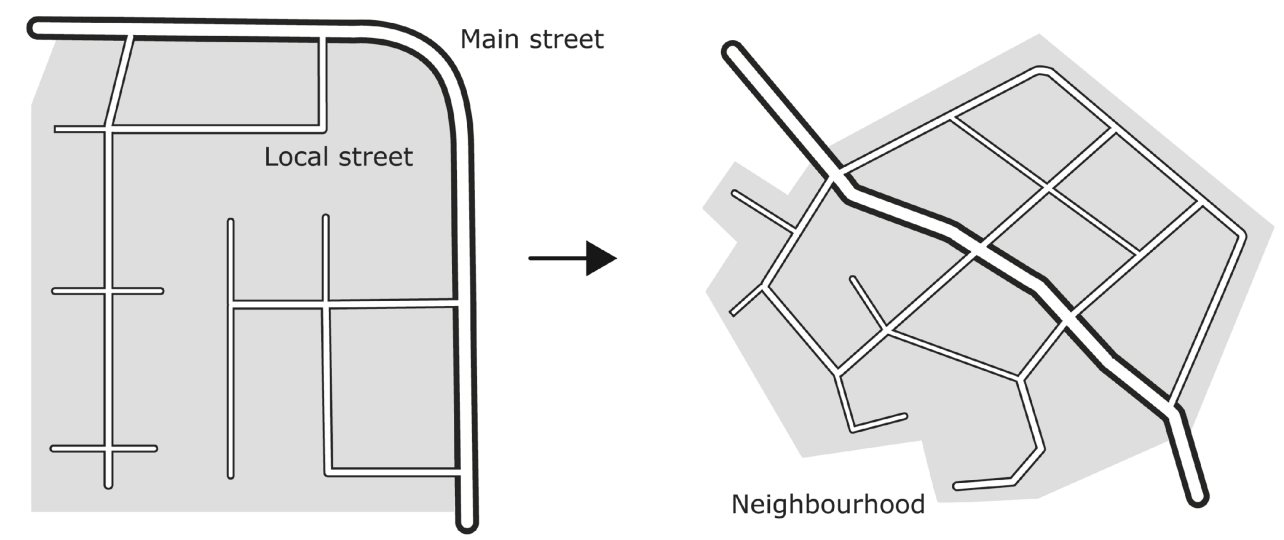

Fig. 7.1 Sketching two different locations of main roads. Planning for the main road to go through the neighbourhood (right) facilitates the spatial potential for the neighbourhood's street life and micro-economy. Where the main road goes around a neighbourhood, neither the social nor economic potential is realised (left), and segregated and mono-functional neighbourhoods are promoted 


\section{(2) Main routes passing through local centres}

This principle is completed by the premise that main routes also have to run through local centres or at least be located tangentially to them. Local vital centres often have a well-connected, dense local street network with a variety of shops and micro-scale businesses. This urban spatial feature is often found in pre-war neighbourhoods. When the main routes run around the local centre, local shops and facilities tend to be limited. Either a local supermarket with necessary supplies or no shops at all are found in such neighbourhoods. This urban spatial feature is often connected to a post-War, modernist neighbourhood (Fig. 7.2).

Fig. 7.2 If the intention is to generate successful local centres with a vital micro-economy and visitors performing a natural surveillance function for social safety, then plan main routes to run through an existing local centre (right) and avoid main roads that go around the local centre (left)
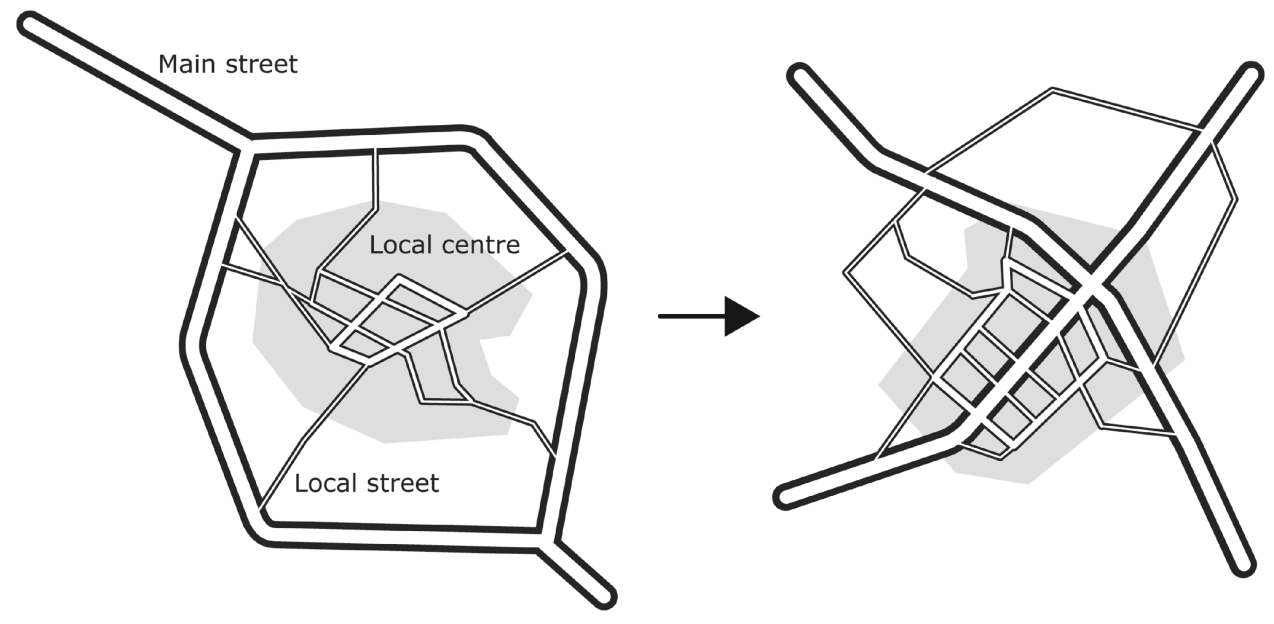

\section{(3) Enhance the network structure of the local urban street pattern}

A network structured generates higher local inter-accessibility compared to a tree structure. Thus, the greater inter-accessibility will contribute to a greater presence of people in the streets. When the main road is located centrally and goes through a neighbourhood or local centre, it creates greater inter-accessibility between locals and visitors and other through-travellers. Again, main routes located through existing centres support a high variety of shops, and therefore, a successful micro-economy. A main route running alongside the edge of a neighbourhood with a tree structure contributes to a sluggish micro-economy. Enterprises located along these main routes often have car-based accessibility (Fig. 7.3).

Fig. 7.3 Enhance a network structure (right) instead of a tree structure (left) for the local street pattern. This will generate high local inter-accessibility
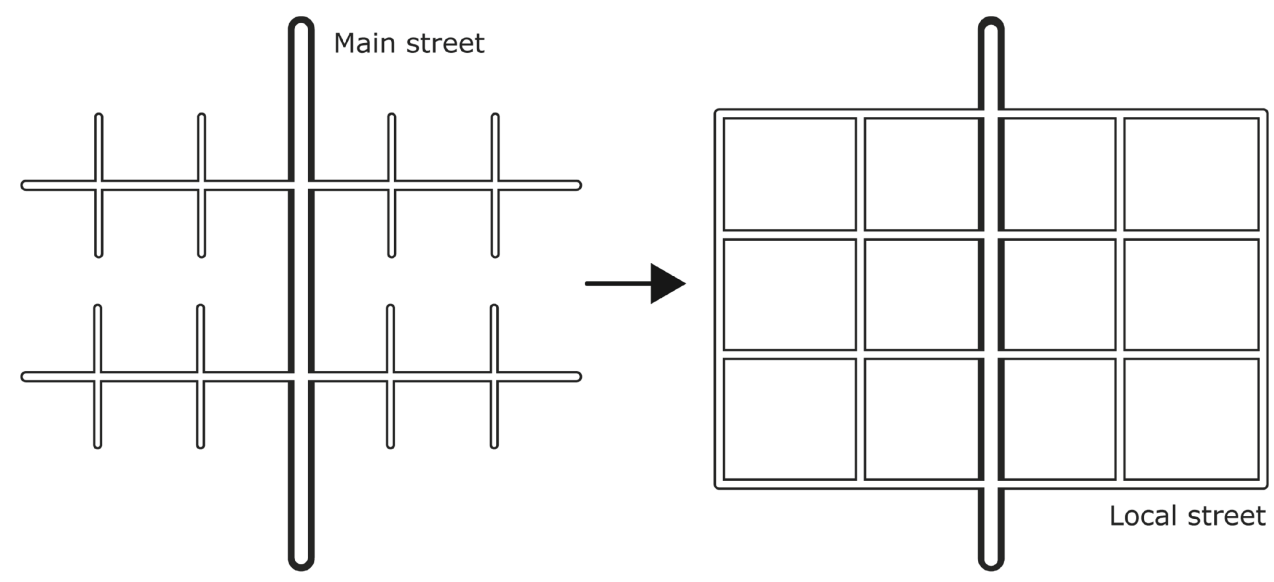


\section{(4) Connect the main routes to all adjacent local streets}

Connecting local main routes to all local streets allows for pedestrian-based shopping streets with a large variation of shops and micro-scale businesses (Fig. 7.4). If the main route has only a few connections to local streets in close vicinity to each other, this creates opportunities for car-based shopping centres. These kinds of shopping centres tend to be located at junctions where the main route(s) are tangential to a neighbourhood. This contributes to mono-functional land use.

Fig. 7.4 The main route has to be connected to all adjacent local streets if the intention is to enhance a large mixture of functions with a high degree of flow of people (right). The main route only loosely connected to adjacent local streets enhances car-based shopping development (left)
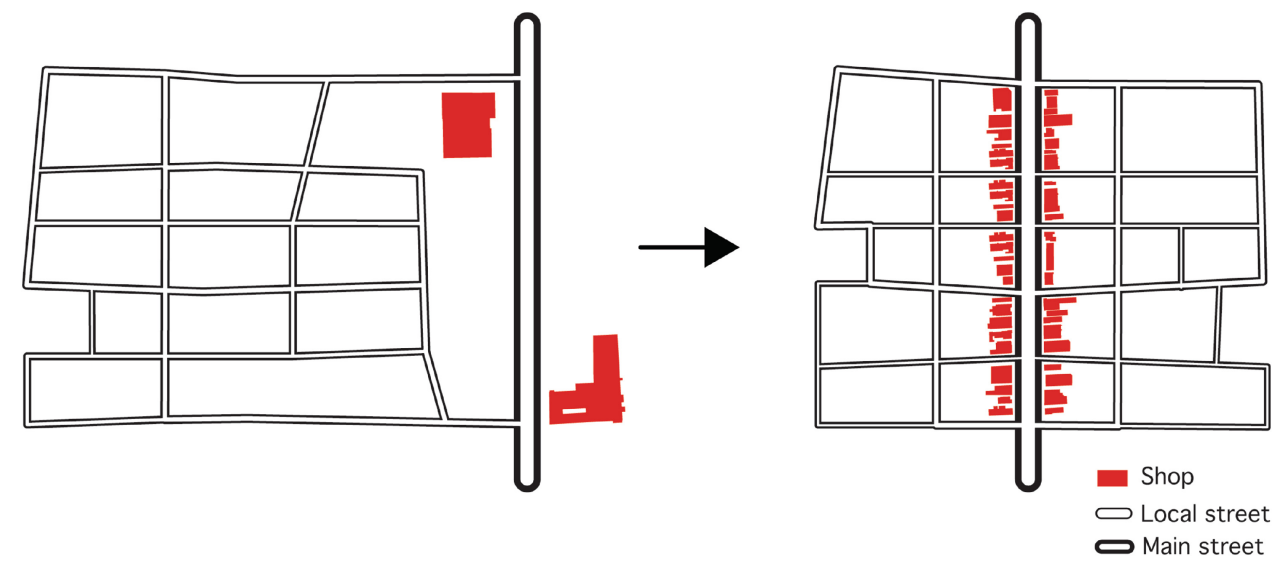

\section{(5) Have buildings with windows and entrances facing towards the street}

Avoid blank walks along streets. Buildings facing the streets enhance the natural surveillance mechanism between buildings and streets. Conversely, buildings with no windows or entrances, buildings with blank walls, or blank walls only along streets contribute to a lack of social control between buildings and streets. This is due to people's avoidance of these streets as part of their routes through neighbourhoods. This invites anti-social behaviour (Fig. 7.5).

Fig. 7.5 Avoid buildings with only short sides facing towards streets (left). Enhance buildings with the long side facing towards streets (right)
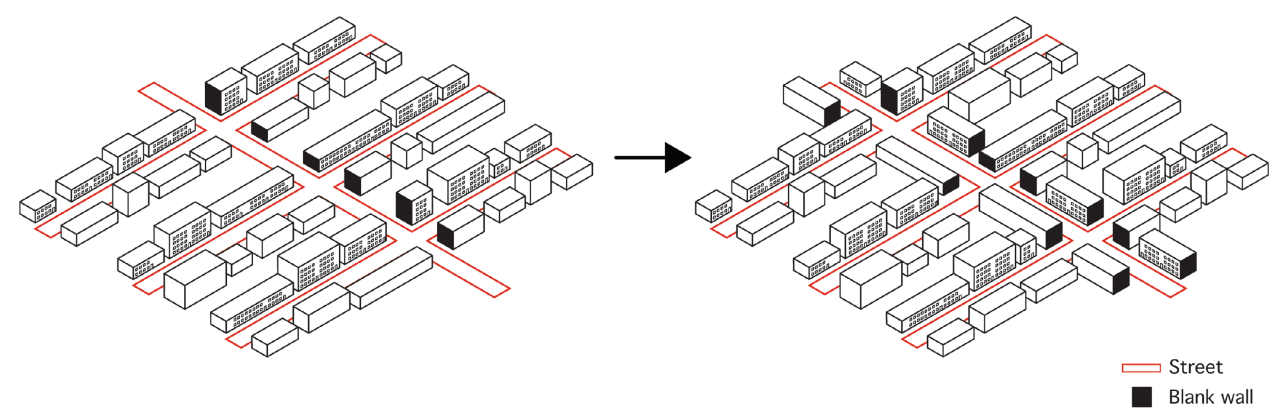

(6) Enhance active functions on the ground floor of buildings

Active functions on the ground floor of buildings such as shops, offices, or dwellings contribute to a co-presence of people inside the building and in the street. This co-presence of people adds to the natural surveillance mechanism, and people inside the building can keep an eye on the street. In contrast, passive functions such as storage and parking garages on the ground level contribute to people-empty streets and a perceived lack of safety (Fig. 7.6). 
Fig. 7.6 Enhance active functions on the ground level to create a high level of co-presence of people inside the building and in the street. People inside buildings can have an eye on the street. Passive functions leave streets empty
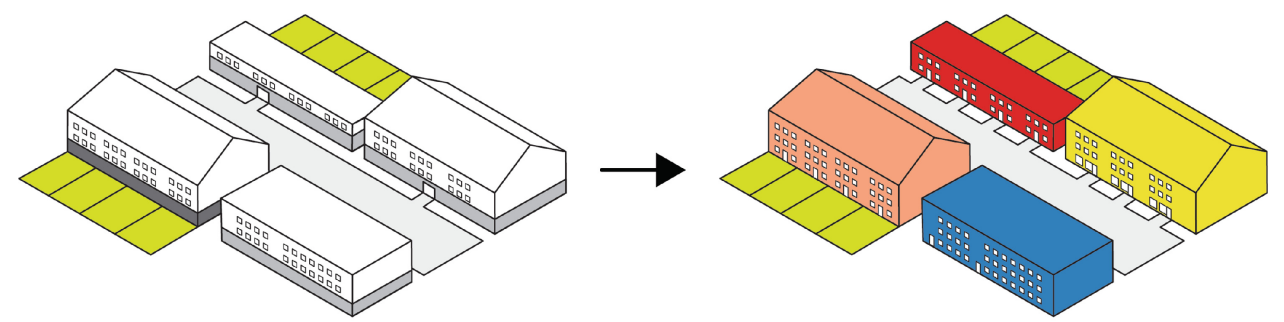

Parking

Storage

Back garden

Street
Dwelling

Shop/Dwelling/Office

Shop

Office

\section{(7) Connect windows and doors directly to the street}

Doors and windows directly connected to the street on the ground floor level add to a natural surveillance mechanism and perceived safety. Streets with a lack of directly connected windows and entrances to the streets are often empty and have a lack of social control and are perceived as being unsafe (Rønneberg Nordhov et al. 2019) (Fig. 7.7).

Fig. 7.7 Windows and entrances directly connected to the street on the ground level contribute to 'eyes on the street' (left). This is a natural surveillance mechanism between buildings and streets

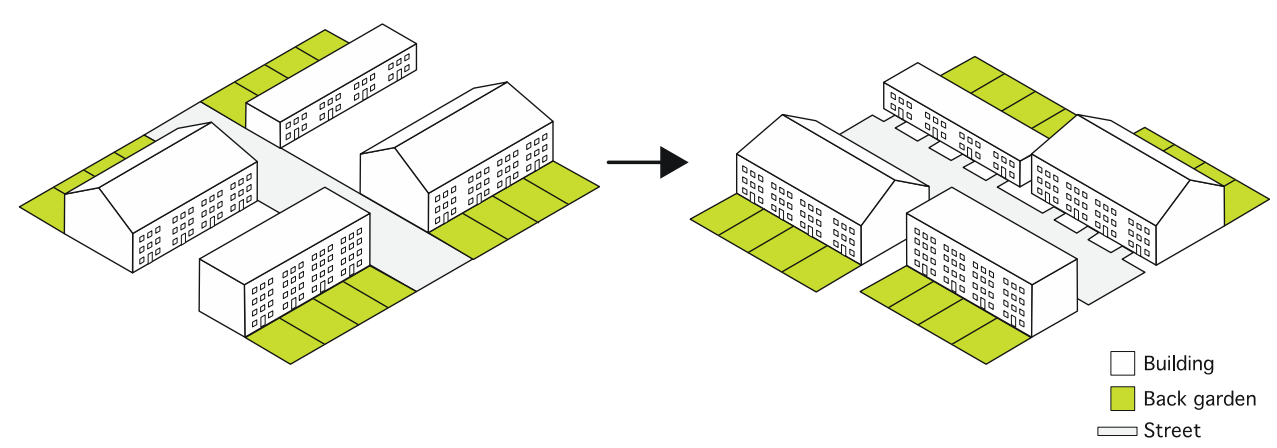

\section{(8) Create a high degree of intervisibility}

Entrances and windows of buildings at ground level, directly connected to the street and facing each other, create a high degree of intervisibility. In cases where the implementation of intervisibility is not possible, planning constituted streets supports a natural surveillance mechanism. Unconstituted streets contribute to empty streets with a high degree of anti-social behaviour and an unsafe feeling (Rueb and van Nes 2009) (Fig. 7.8).

Fig. 7.8 A high degree of intervisibility in a street (right) and no intervisibility in a street (left)

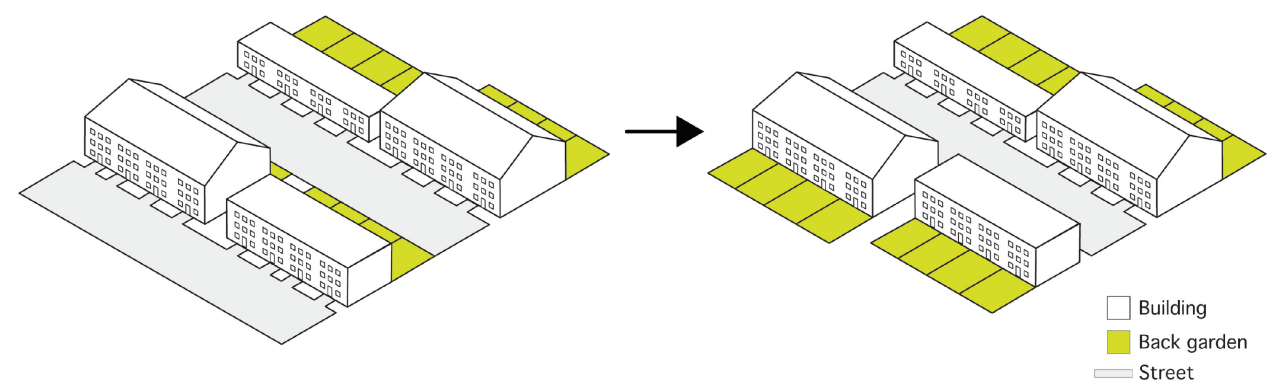




\section{(9) Create direct connections between public and private spaces}

Enhancing a high degree of direct connections between public and private spaces enhances social control and natural surveillance between residents and people's activities in streets. A large number of semi-public or semi-private spaces between a dwelling and a public street contributes to a lack of street life and the feeling of gated communities (Fig. 7.9).

These principles are seemingly applicable for most countries because they are all about spatial interfaces on various scale levels. However, in some countries, poverty issues make these micro-scale principles difficult to implement. Examples of this can be found in many South American cities, and to some extent in some African cities. Therefore, the local social and cultural context needs to be studied carefully.

Fig. 7.9 The topological depth between the private and public space has to be shallow when the intention is to enhance street life (right). Large semi-private and semi-public spaces support deserted streets (left)
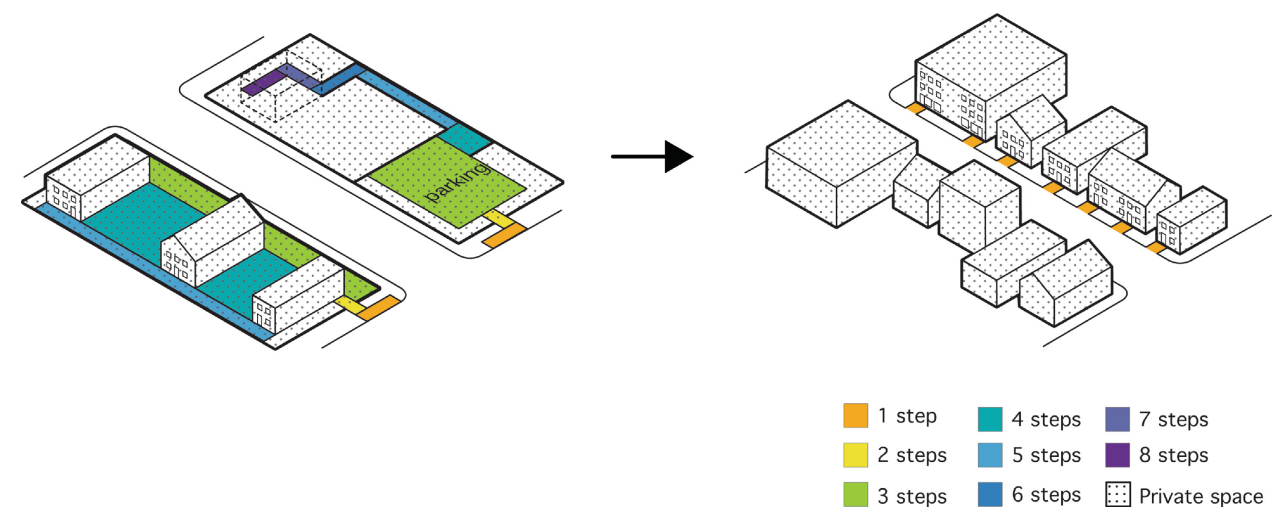

\subsection{Learning from Past Errors}

Most important when applying space syntax in urban design projects is to learn from past errors. This will further develop the application of space syntax in practice for designing well-functioning spaces while avoiding falling into the same traps as in the past. However, there exist a large number of urban projects around the world that have been built from the 1970s onwards that do not function as intended. In particular, three main errors from modern urban design and planning practice can be identified by the application of space syntax analyses (Karimi 2009):

\section{(1) Implementing urban motorways instead of urban boulevards}

On a macro-scale level, the first error is that urban planners, urban designers, and in particular, road engineers implement urban motorways as main streets instead of urban boulevards that focus on pedestrians. The spatial parameters of a vital and vibrant main street are an integrated street with both vehicle and pedestrian movement that is well connected to its vicinity, as well as to the whole city. Local and global movements are mixed in the way buildings and streets are permeable to one another. Instead of the old well-connected main street, urban motorways or fast highways with high traffic safety standards separating global and local movement are implemented in urban areas. There is no permeability from adjacent buildings and streets to these urban roads or highways. The effect is a suppressed movement economy that is based on private car dependency (Karimi 2009). Figure 7.10 illustrates the main boulevard in Stockholm and an urban motorway in Brussels.

On a micro-scale level, we tend to plan parking streets instead of dwelling streets. The parking of cars dominates the streets instead of shaping opportunities for all kinds of people to use and be in the streets. When the cars are parked at a 90or 45-degree angle to the street, the cars dominate the streets. When the cars are parked parallel with the streets, the streets facilitate a balance of users (Fig. 7.11). 
Fig. 7.10 Example of an urban main street in Stockholm (left) and an urban motorway in Brussels (right)
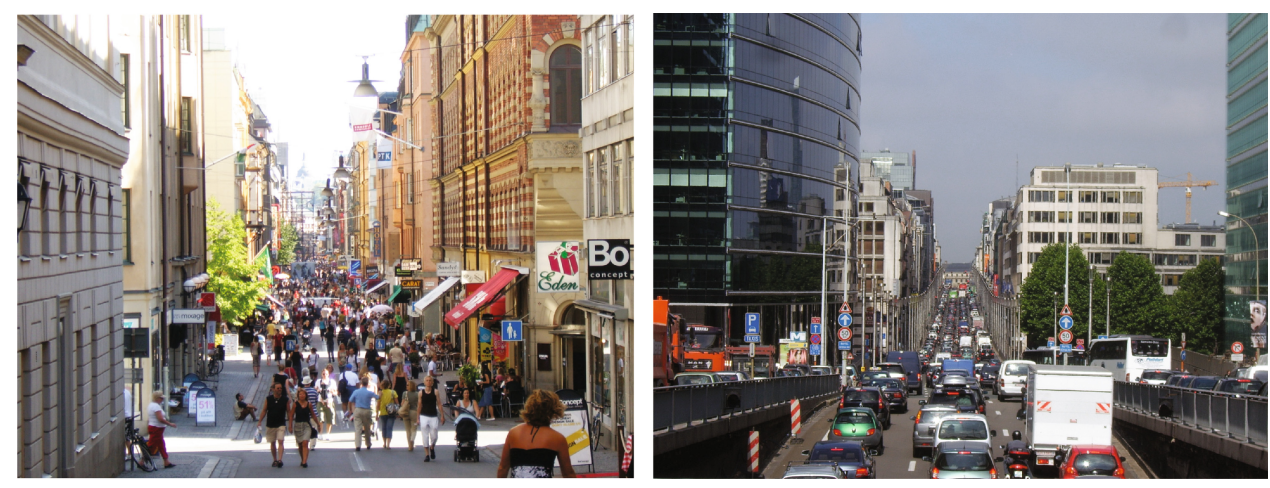

Fig. 7.11 Example of a balanced residential street (left) and a car-parking street in the Netherlands (right)
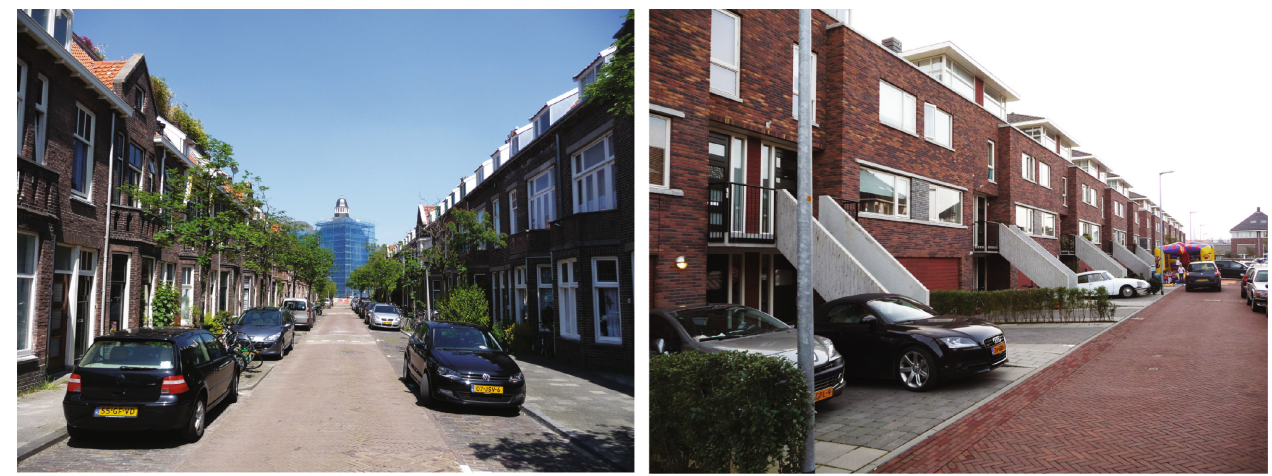

\section{(2) Separation of land uses into zones}

The second error that often occurs in modern(istic) planning practice is the separation of land uses into zones. In historic town centres, there is a mix of land uses in short walkable distances to one another, which minimises journey lengths. In modern planning practice, land uses are zoned into different areas, which creates longer journeys than in historic urban areas. The effect of these kinds of plans is a street and road network with complicated movement routes from everywhere to everywhere else (Karimi 2009). The metric length of the street and road network is much longer than in traditional urban area. A street network of this kind enhances private car dependency, which contributes to new and often inefficient urban strategies for how to handle increasing private car ownership.

Figure 7.12 depicts the historic and modern centres of the town Delft in the Netherlands. The active transport modes of walking and cycling between the various functions in the historic centre are more efficient compared to the use of car and tram as the best transport mode for the modern centre in Delft. This tendency can be identified in many cities around the world.

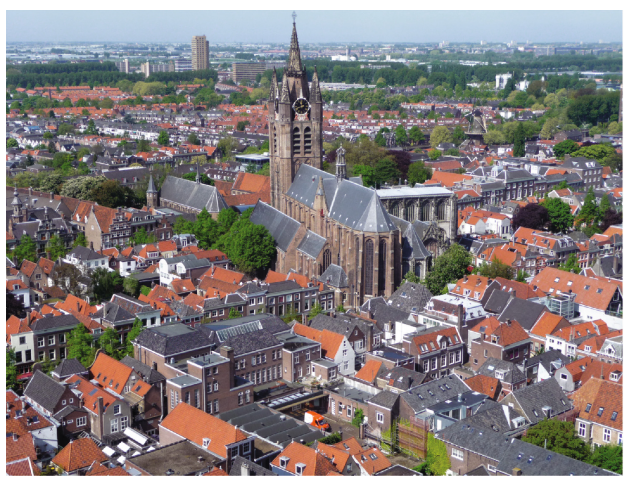

Fig. 7.12 Traditional urban areas tend to have a mixture of dwellings and commercial and office functions, whereas modernistic urban areas embrace separation of functions. This is illustrated in two examples in

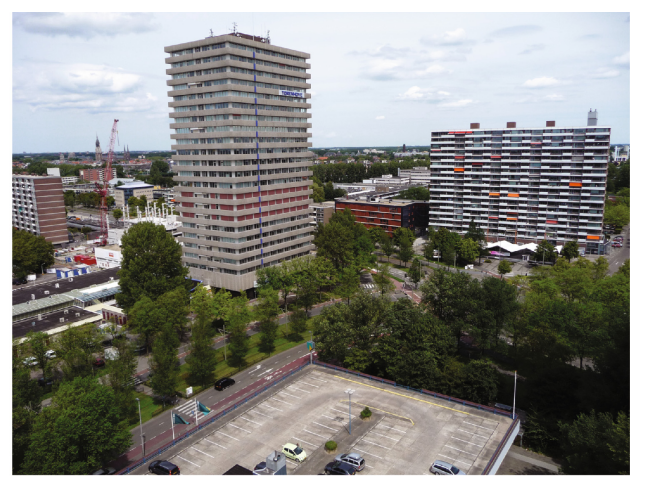

Delft, the historic centre (left) and the modernistic centre De Hoven Passage in Poptahof (right) 


\section{(3) No active frontages}

On a micro-scale level, the third error in modern architecture practice is a lack of active frontages. Newly implemented buildings in urban areas are anti-urban in the way these buildings are not street dependent (Karimi 2009). Their entrances and windows are turned away from the public street, and this tendency can be identified in both shopping and residential buildings. Old urban buildings have windows and doors facing towards the streets and are directly permeable from the street. These kinds of buildings support a high degree of walkability and street safety.

In present modern architectural practice, buildings tend to have blind walls or blank frontages facing the street. Often, new residential areas and shopping centres are built to facilitate private car accessibility at the cost of short pedestrian journeys. In short, the social urban life between buildings is replaced with transport. Figure 7.13 shows an example of a traditional urban dwelling and a modern urban dwelling. For the modern urban dwelling, the main access to all the apartments is provided through one main open port. The main entrance is from the back yard of the building.

Fig. 7.13 Example of a traditional urban dwelling in Delft (left) and a new urban dwelling in Greifswald (right)
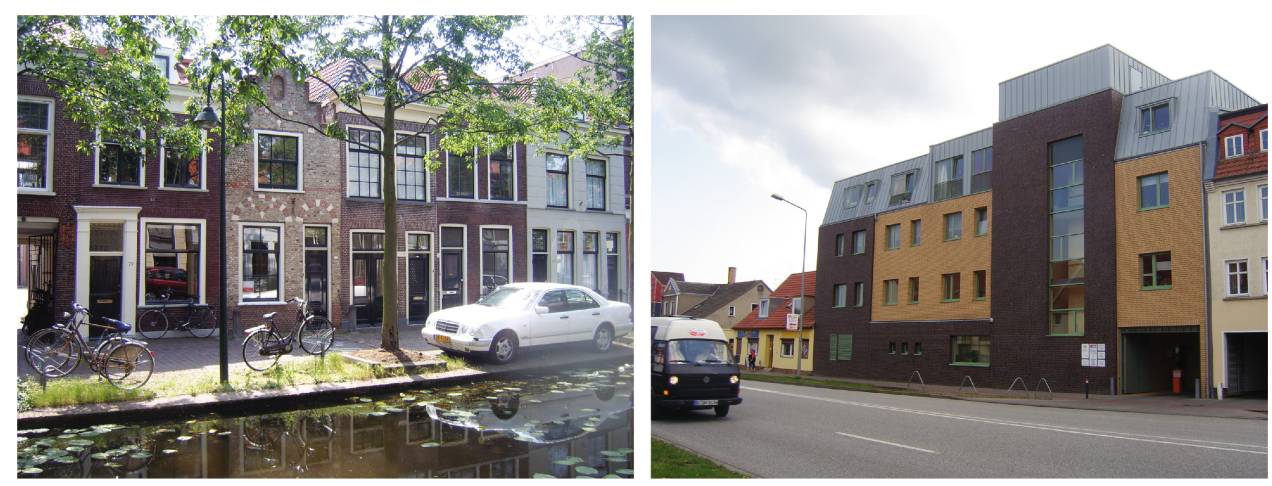

Figure 7.14 shows the same principles for a traditional shopping street where all shops have direct access to the street and a modern shopping mall with only one main entrance to all the various shops located inside the building.

When these three main mistakes on three different scales appear, the effect is that newly implemented urban areas tend to consist of fast highways separating mono-functional areas from each other with buildings that lack active frontages. Knowledge derived from space syntax research and applied to urban design, in general, is fruitful for creating successful urban areas by applying a people-centred design approach.

The generative socio-economic dynamics of urban space to some extent allows the prediction of certain socio-economic effects of urban planning and design proposals. Furthermore, a post-evaluation of implemented urban planning and design proposals for projects where space syntax consultancy was involved contributes to theory building and methodological development. The application of space syntax in consultancy goes hand in hand with research results where space syntax is used.

Fig. 7.14 Example of building facades in a traditional shopping street (left) and a modern shopping building (right), both located in Utrecht
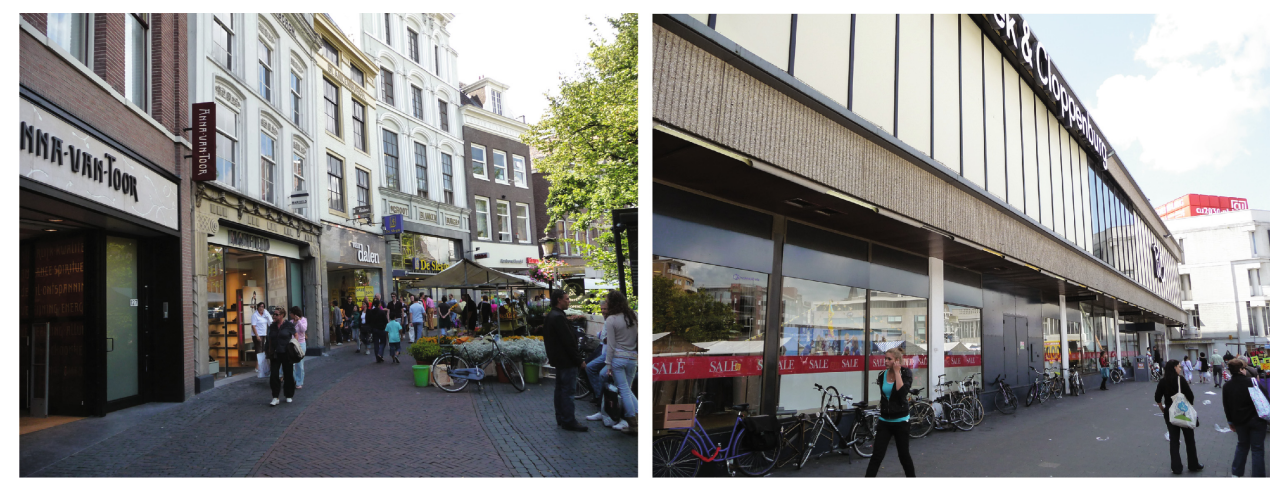


\subsection{Examples from Practice}

In the middle of the 1990s, the first applications of space syntax in consultancy practice were carried out. At that time, segment analysis was not yet developed. In urban planning and design practice, the time span from consultancy, to concept, to developed design, and finally to construction can take — based on the size of the project — up to decades. This and the complexity of the projects also define the timeframe for the decision-making process in terms of stakeholders, finances, and political will and administration from a local to a citywide level.

Space Syntax Ltd. London in collaboration with the Space Syntax Laboratory at the University College London has carried out several consultancy projects with the purpose of improving the urban public realm from individual neighbourhoods to large metropolitan areas. Examples of projects are the master plan of Jeddah, the redesign of Woolwich Squares in London, the regeneration of the areas around King's Cross Station in London, the upgrade of the Old Market Square in Nottingham, the evaluation of the location of the Millennium Bridge in London, and the creation of spatial strategies for the Chinese city of Changchun, among others. Further information can be found on Space Syntax Limited's website.

In the following, we discuss four projects, namely the public realm design for Trafalgar Square, the new highway link through the Dutch city of Leiden, the strategic plan for railway stations for North Holland, and the use of space syntax in densification strategies in the Norwegian city of Bergen. The examples are used to show how space syntax is applied in various urban design, strategic planning, and consultancy projects.

\subsubsection{Public Realm Design for Trafalgar Square, London, United Kingdom}

The space syntax method was applied to the redesign of Trafalgar Square in 1996, which was led by the architect firm Foster +Partners. This project is so far one of the most successful realised projects where space syntax played a major role in the decision-making process, and it serves as one of the first strong examples of how space syntax works in practice. Both before and after the square renewal, people observations and registrations were carried out. This allowed the designers to test the 'before and after' space syntax model against empirical data. In the 1990s, only axial analyses and one-point isovist analyses were applied.

The initial analysis of pedestrian patterns showed that locals avoided the centre of Trafalgar Square and that tourists failed to make the journey between Trafalgar Square and Parliament Square. The pedestrian movement model by Space Syntax Ltd. London team allowed a quick diagnosis of the problems throughout the master plan area. Departing from there, design solutions were developed (Fig. 7.15).

Fig. 7.15 Trafalgar square in 1996. Most of the space was empty most of the time. Source Stonor (2011)

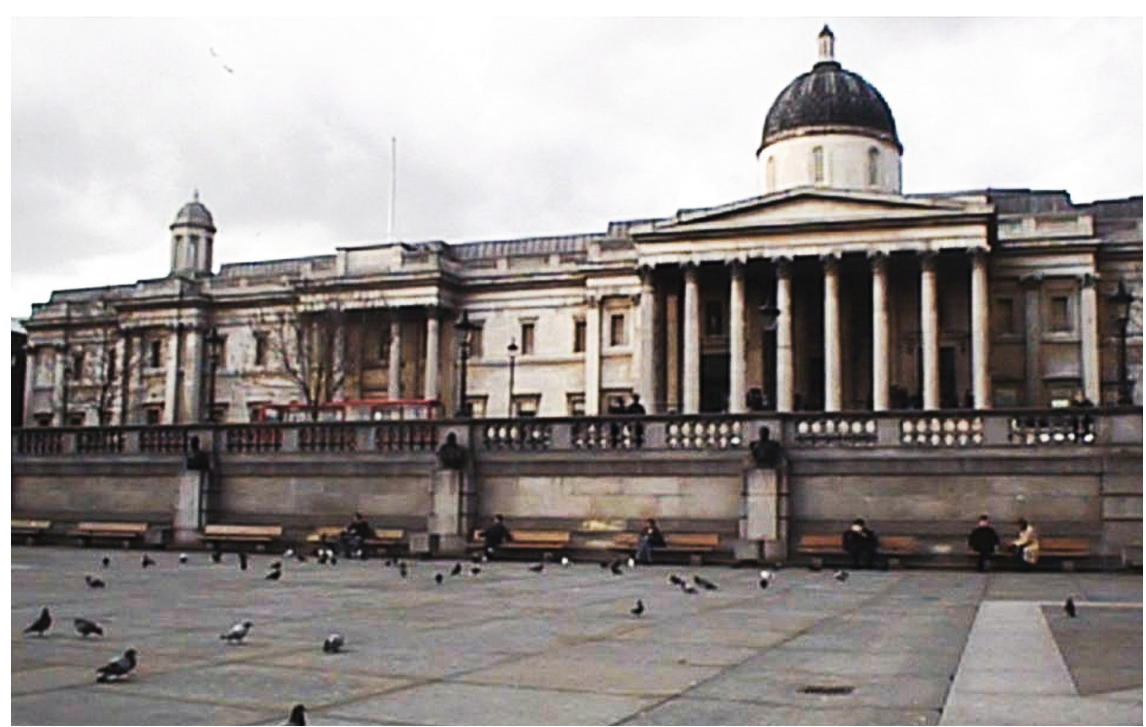


The empirical data from people observations and the space syntax axial analysis showed that most of the pedestrian flow took place at the edges of the square. Accessibility to the square was complicated and street crossings were dangerous. In addition, the heart of Trafalgar Square was only reachable by entry points consisting of two staircases running along a wall and facing away from the entry points of the square. Figure 7.16 highlights how the movement was pushed around the edges of the square due to the physical design of the space (left). The design strategy was to bring movement to the heart of the square via a central staircase and the design proposal enhanced the natural movement through the body of space.

An axial map of the pedestrian routes was made, and the before and after traces and axial model depict the revitalisation of Trafalgar Square. As can be seen from Fig. 7.16, both axial models are coherent with the empirical data. The global axial integration analysis of the square is coherent with the results from observations of people's routes. After the design implementation, the spatial integration of the square increased and people are now moving through the body of the square (Fig. 7.17).

Fig. 7.16 The spatial challenge and design strategy for Trafalgar Square. (original: Stonor 2011; redrawn by authors)
Fig. 7.17 Axial model and pedestrian movement registrations before and after the design implementation for Trafalgar Square in London (Dursum 2007). Source Space Syntax Ltd. London

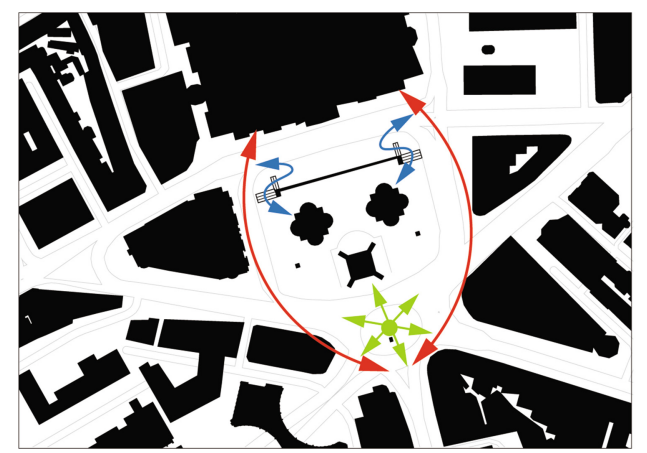

Design issue

Movement was pushed around the edges of the Square by the physical design of the space, such as indirect staircase links.

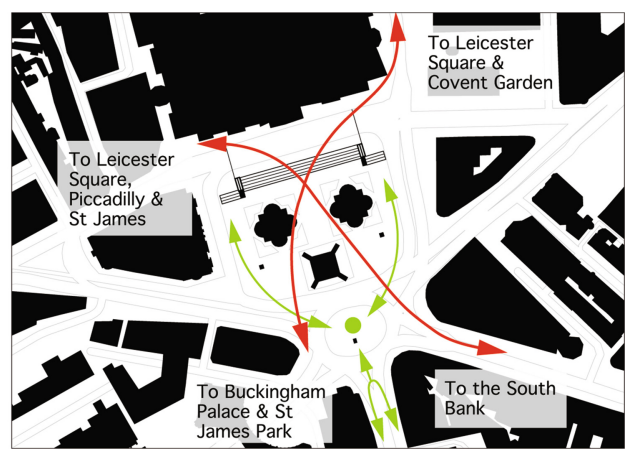

Design strategy

The design strategy, developed with Foster + Partners, was to bring movement through the heart of the Square via a new, central staircase.

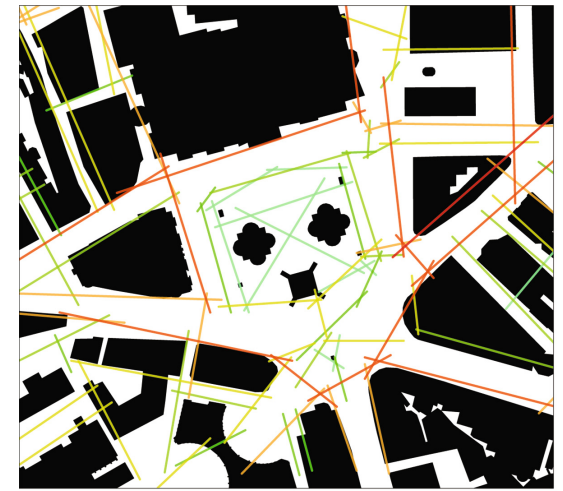

Axial analysis before implementation of the plan

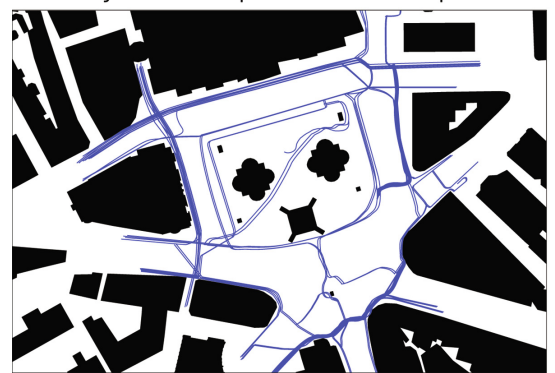

Registrations of human movement in February 2001

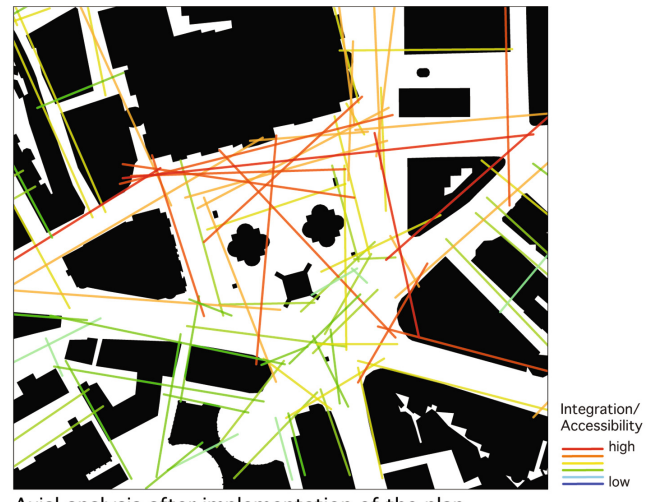

Axial analysis after implementation of the plan

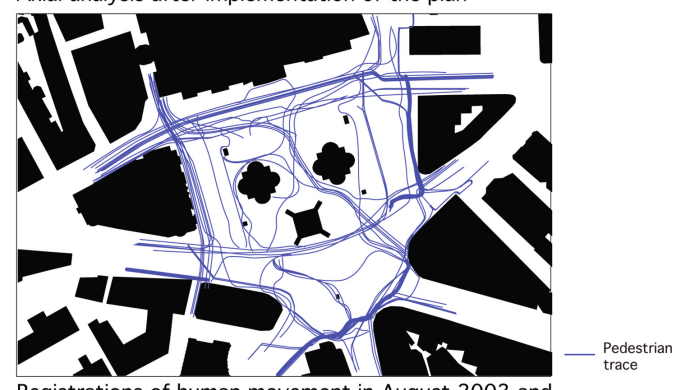

Registrations of human movement in August 2003 and February 2004 
Space Syntax Ltd. London and the Space Syntax Laboratory at the University College London own detailed registrations of pedestrian flows in several central areas in London. These registrations are correlated with results from space syntax analyses and highlight that the higher the numerical integration value, the greater the numbers of people in the streets. This knowledge allowed the prediction of how the urban design proposal for Trafalgar Square might increase or decrease the presence of people for each path (Fig. 7.18).

Fig. 7.18 The forecast model for a potential increase in the co-presence of people for every route for Trafalgar Square after the design implementation. (original: Stonor 2011; redrawn by authors)

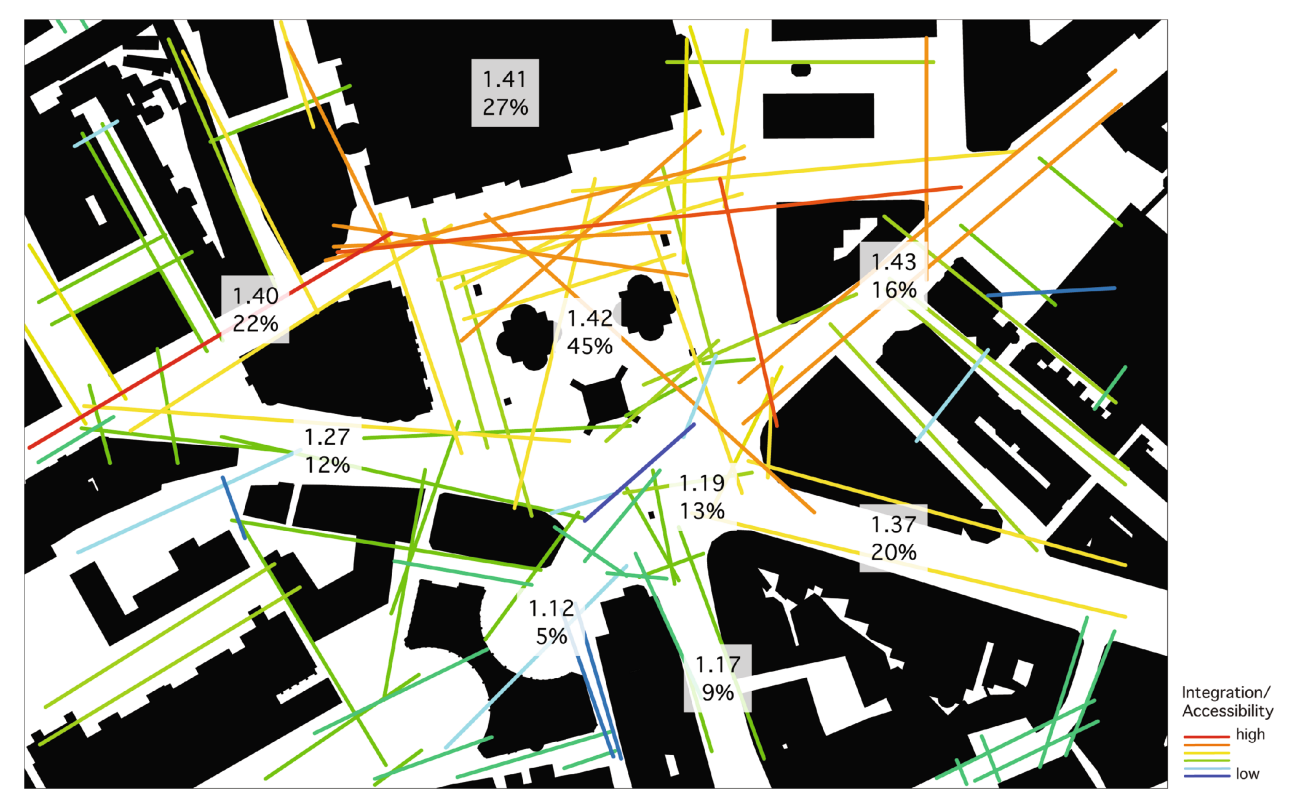

For the redesign of Trafalgar Square, the gallery with the previous staircase had to be removed to install the central staircase, which required permission from London's conversation authorities. For communication and negotiation in the decision-making process, in addition to the evidence-based models, 3D visualisations of the future impact including people's usage were also made. Figure 7.19 (left) shows a Photoshopped image used for convincing decision-makers, and (right) the first day of opening of the redesigned square based on space syntax methods and theories. Today, Trafalgar Square is very well used by locals and tourists.
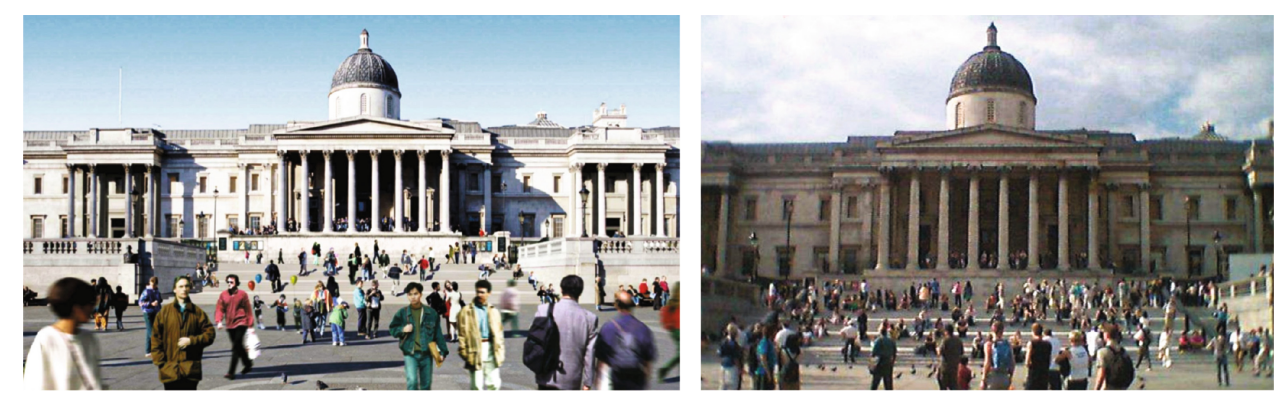

Fig. 7.19 The Photoshopped image of Trafalgar Square used for convincing the decision-makers (left) and a photo taken the first day of opening (right). Source Space Syntax Ltd. London 2011

The Trafalgar Square project proved that space syntax works well for urban design projects, and since the renewal, the square has become an important meeting place for tourists as well as for locals. The key was to improve accessibility to the square and to 'steer' the natural pedestrian flow through the square instead of around it. Since 2010, Space Syntax Ltd. London has been involved in numerous projects on the redesign, regeneration, and improvement of urban areas on various spatial scales. 


\subsubsection{Evaluating a New Road Connection Through the City of Leiden, the Netherlands}

The space syntax method was applied in a brainstorming workshop for option testing of new road links for the Dutch city of Leiden in 2005 (Van Nes 2007). This project started with a workshop with various stakeholders, researchers from TU Delft, urban designers, and representatives from the province, the municipalities, and the Dutch Ministry of Housing (VROM). The focus of the space syntax analyses was to test out how various new proposed road links might affect existing and new potential centres on a citywide scale.

Leiden is located between two highways, both running in a north-south direction. However, effective east-west connections are lacking for Leiden, as well as for its surrounding municipalities. During rush hours, the city suffers from heavy congestion on all its main routes. For 20 years the decision-makers in the region were discussing how and where to implement an effective east-west connection. In 2005, four different proposals were discussed during the workshop. As an experiment, an axial global integration analysis was conducted for the existing situation (the baseline study) and for four different alternatives for the new road link named W4 (option testing).

Figure 7.20 shows a global axial integration analysis of Leiden with its surrounding municipalities. The most integrated axes are the highways and some routes leading into the centre of Leiden. As can be seen from the map, the city centre is easily accessible from the northern highway. There the Bio-science park is located. The white dots show the locations of the headquarters of various large company headquarters. These companies tend to be located in locally integrated town centres or at integrated nodes along the highway.

Fig. 7.20 Global integration analyses of Leiden with its surrounding municipalities in 2005 (the baseline map)

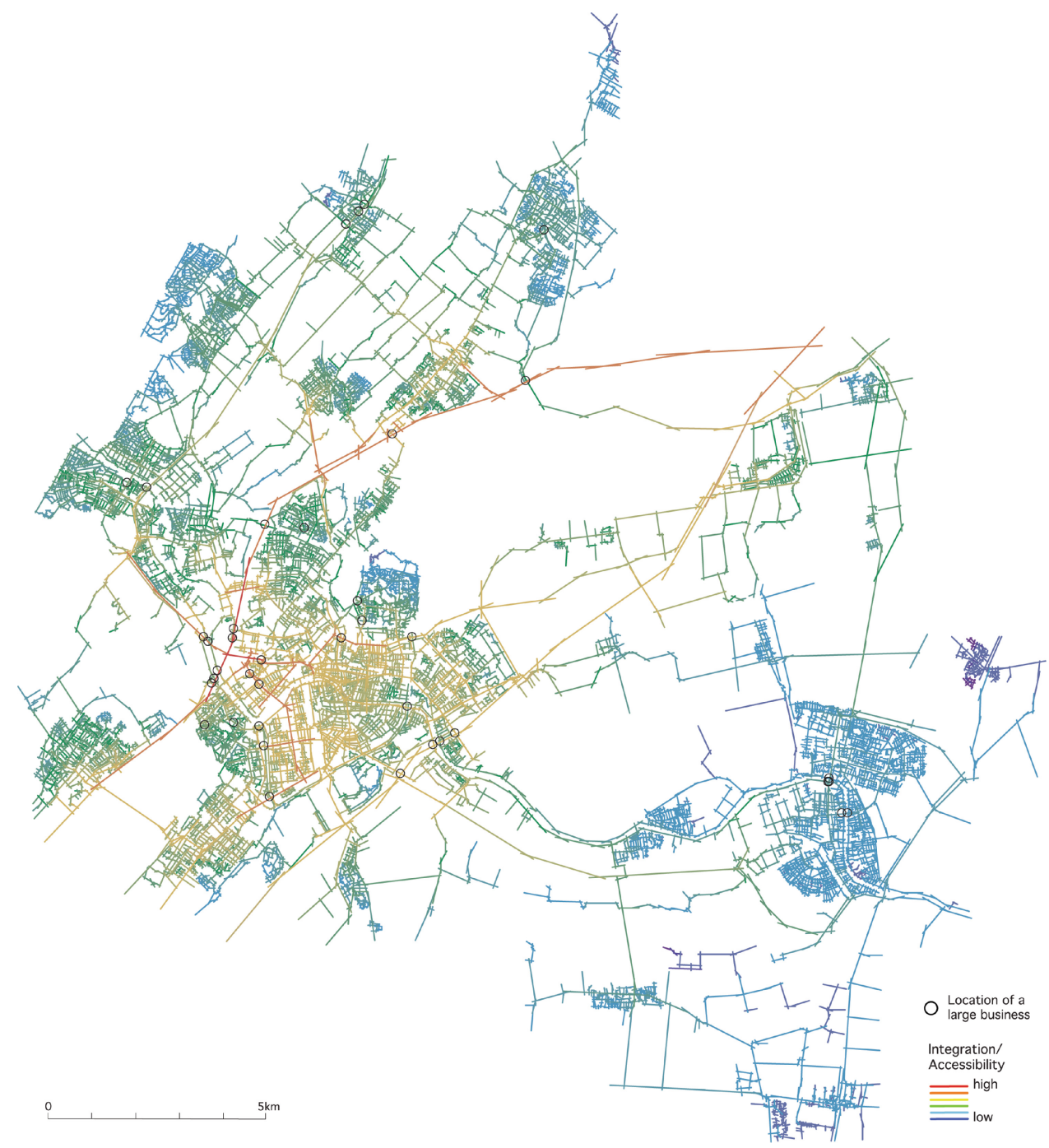


Figure 7.21 shows the results on how these road alternatives might affect the vitality of Leiden's existing centres. Here the global axial integration analysis is used. The location of potential economic centres depends on how the road link is inter-connected to the local main route network and how accessible the main city centre is from the new road link. Strategies 1 and 2 contribute to improving the vitality of the existing old historical city centre of Leiden, whereas strategies 3 and 4 contribute to the emergence of new economic centres located along the highways (Van Nes 2007).

Fig. 7.21 The use of space syntax in testing out how various new road links might affect the centralities in Leiden (option testing). The black circles indicate large businesses

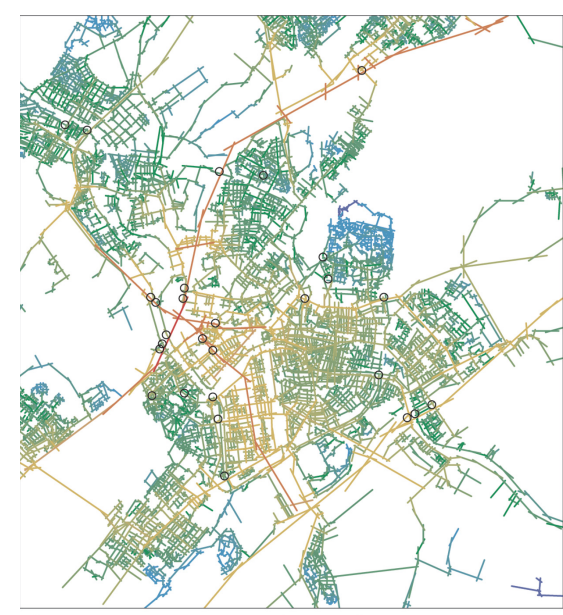

Alternative 1: Improve and upgrade existing connection between $\mathrm{A} 4$ and $\mathrm{A} 44$ as proposed by the municipality and the province

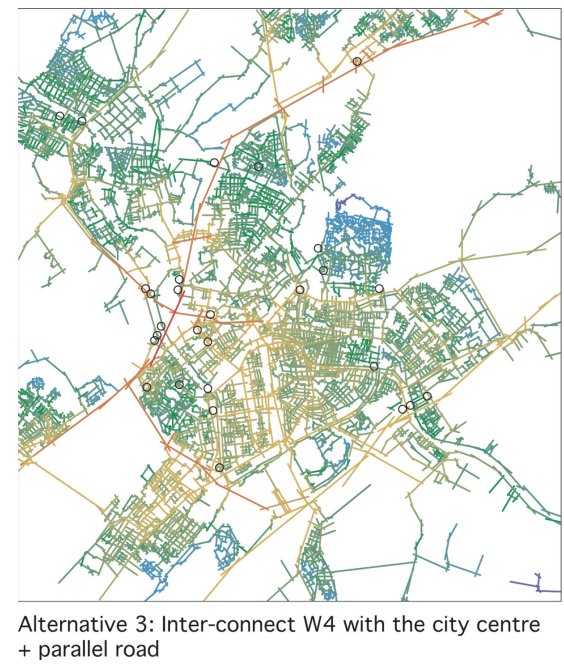

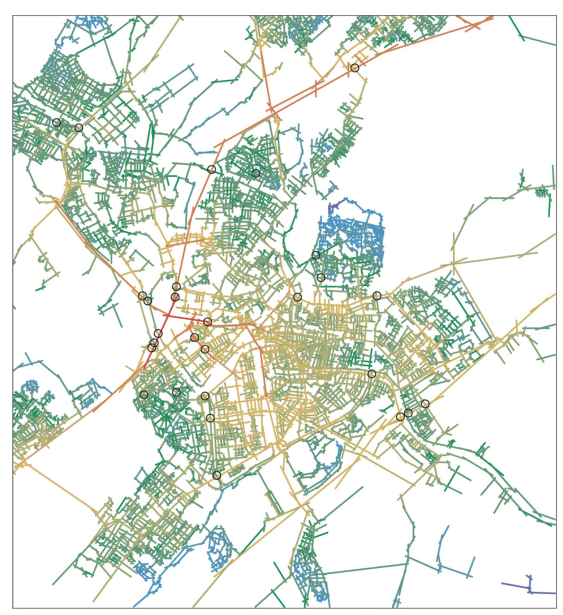

Alternative 2: Inter-connect W4 with the city centre

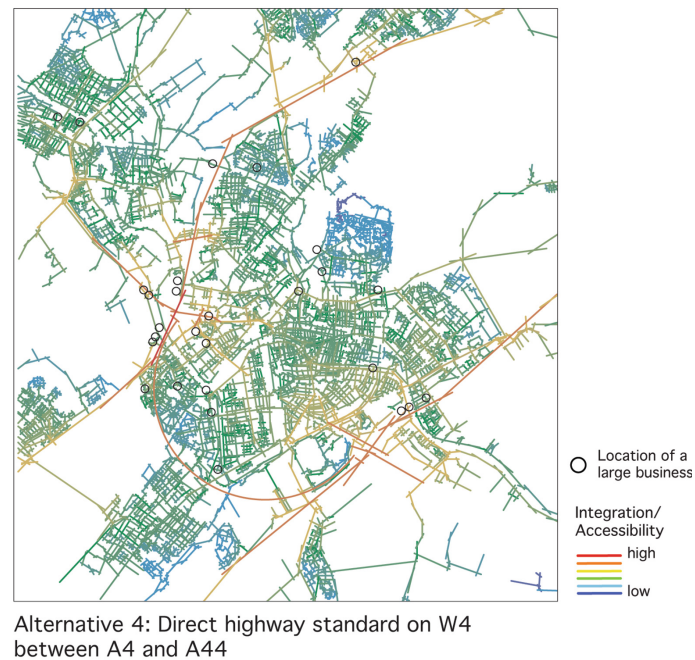

The space syntax analyses of the impacts of various proposed road links through Leiden from 2005 were done using the axial sight line method. Later on, in 2011, the discussion was centred around alternatives 1 and 3. The province of South Holland wanted alternative 3, while the business owners with their local action group wanted alternative 1 . Alternative 1 consisted of a tunnel under the existing avenue (Churchill Avenue) for through traffic, with the local traffic being distributed on the avenue that is well connected to all streets in the vicinity. The business owners feared that they would lose customers with alternative 3 and asked for a new scientific report that they could put on the table for the decision- makers. Alternative 3 consist into lead all the car traffic away from the city centre.

Therefore, in 2011, space syntax analyses with angular weighting and a detailed description of how each of the alternatives might affect the various local centres were carried out. The results of the angular weighting of the segments showed the same results as in the 2005 analyses; alternative 1 would increase the vitality of all centres, whereas alternative 3 would do the opposite (Van Nes and Stolk 2012a, b).

In spite of the evidence from the space syntax analyses, the decision-makers chose alternative 3. This solution is in line with the road building planning and implementation practice carried out over the last 50 years. Space syntax was then too 
unknown for the decision-makers, and they were relying on the traffic modelling prognoses carried out by the road engineers. At present, the construction of the new road link (alternative 3) is on-going, and we are waiting to see how this will affect the various centralities in Leiden in the future.

\subsubsection{The Densification Strategy Plan for Bergen Municipality in Norway}

The space syntax method was also useful in the overall densification strategies for the Norwegian city of Bergen in 2016 (De Koning et al. 2017). Here, two researchers from Western Norway University applied angular choice analyses with a high and a low metric radius. The focus of the space syntax analyses was to test out the spatial accessibility profile of various neighbourhoods with aggregated angular choice analyses and to use the results of the analyses to give recommendations for densification strategies.

The project was initiated by Bergen municipality, which wanted to explore where and how to densify in existing urban areas. The aim was to use the outcomes in future land use and policy planning as a strategy for densification in the central areas of Bergen. Inspired by the 'Denser Stockholm' project (Spacescape 2013), a 'Spacescape' analysis was made using a 'densification pie chart' to identify both the need for densification and where there is freedom to make it happen. How to densify in those areas depends on the degree of accessibility of the street network and public transport, as this inquiry showed. To that end, the space syntax method was included in the research project.

The project started with the identification of the types of densification actions proposed by the municipality. Three types of densification actions were identified: intensification, transformation, and expansion. The intensification strategy entails identifying densification potentials in existing urban areas without changing the entire built environment. The transformation strategy concerns identifying and assessing densification potentials of larger urban areas that would require a functional transformation, such as harbour fronts, goods terminals, and industrial estates. The expansion strategy intends to find densification opportunities in previously unbuilt areas within the city borders. In the Bergen case, these are often found on the mountain slopes, where development had not previously been considered due to costly technical challenges (De Koning et al. 2020).

Following the theory of the natural movement economic process (Hillier et al. 1993, 1998), it is to be expected that the highest potentials for densification outside the city centre are found around the main routes, the local centres, and the public transport stops. Local discrepancies may be found and can likely be attributed to the unique landscape elements such as the mountain slopes and fjords surrounding the city. These elements are also responsible for the characteristically capricious road pattern in the city, which follows height lines to keep gradients acceptable from a road-engineering point of view.

Figure 7.22 shows the baseline studies of Bergen with a normalised angular choice analysis with a high metric radius $(5000 \mathrm{~m})$ and low metric radius $(500 \mathrm{~m})$. First, the results were imported into GIS, and the various space syntax values were

Fig. 7.22 Normalised angular choice analyses of the current situation of Bergen with a high (left) and a low (right) metric radius
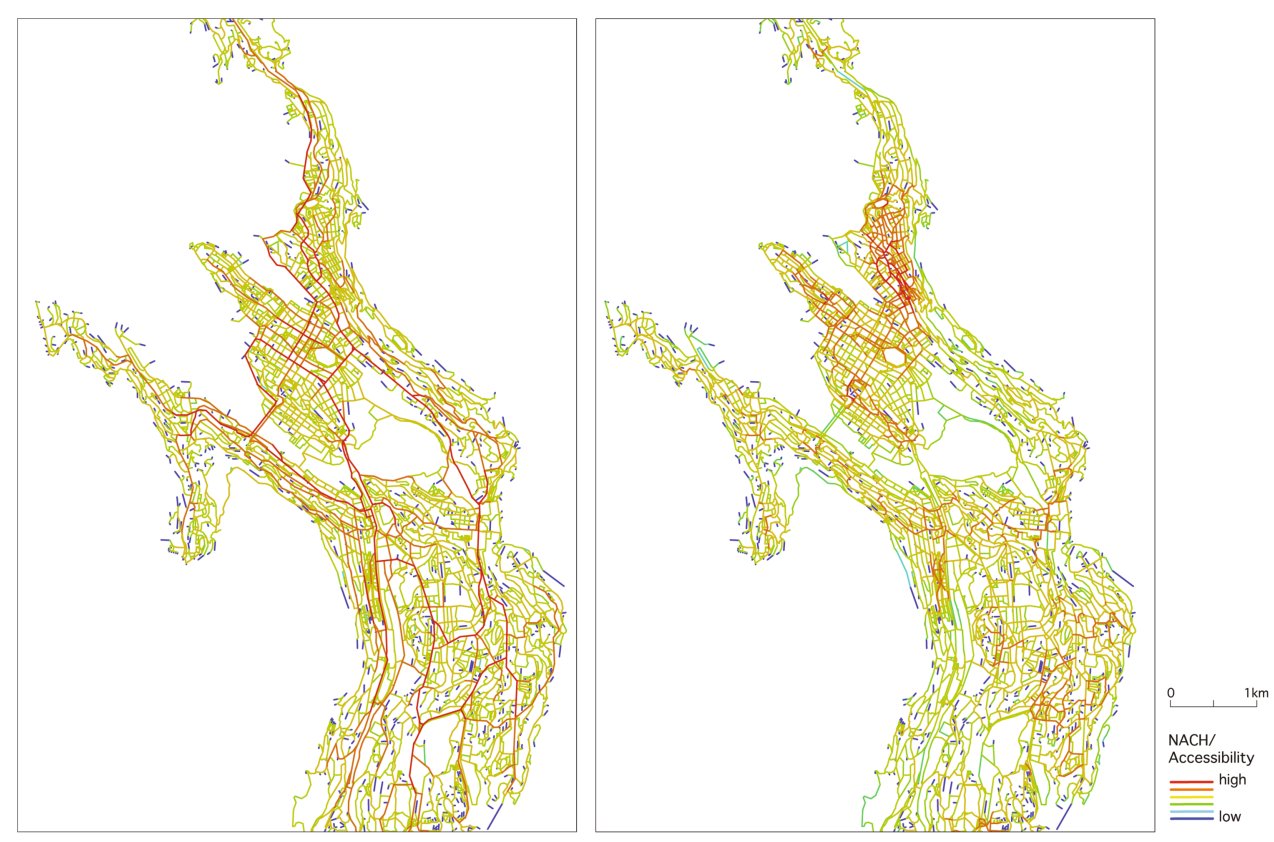
added to the adjacent plots. The lines with the highest values decided the values of the plots. Then the space syntax values were grouped into high and low values on the plot level for both normalised choice analyses. This is the basis for aggregating both spatial analyses with one another.

Figure 7.23 shows the outcomes of aggregating the angular choice analyses with a high and low metric radius. Four different types of urban areas are shown. For each of them, different densification strategies can be made for Bergen on where and how to densify. They are all dependent on the degree of local and global accessibility of the street and road network.

Fig. 7.23 Densification strategies in Bergen

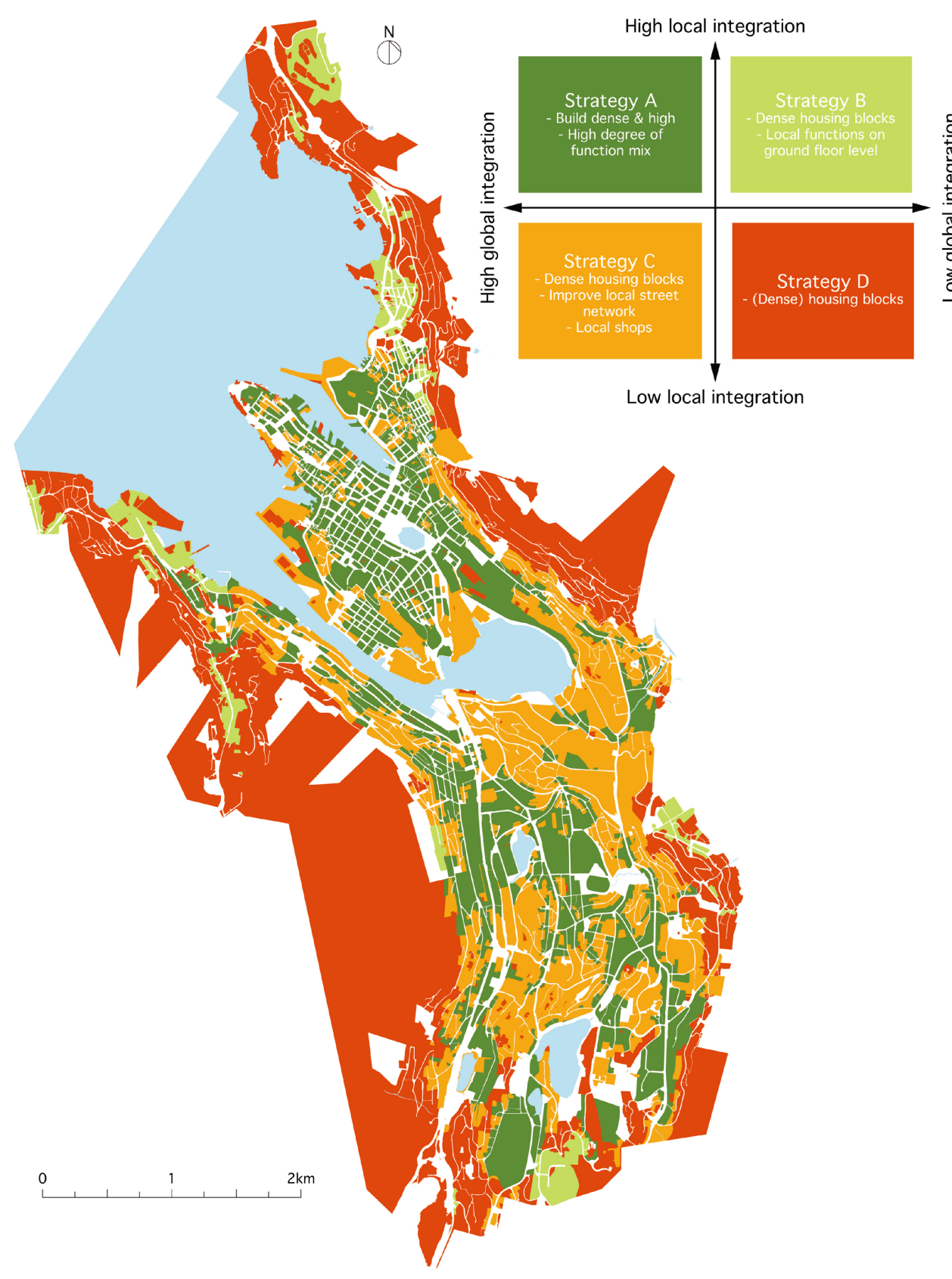


The strategy A areas have high local and high global choice values of the street and road network. Often these areas are located in city centres with high degrees of function mixture and high densities of buildings. Where extra space becomes available, these areas can be transformed with a high density of built mass. This can include high-rise buildings. The aim is to provide land use plans that allow a wide range of different usages, in particular on the ground floor level. Areas suitable for this kind of development in Bergen are the city centre, the harbour areas around the city centre, and the old industrial areas.

The strategy B areas have high local, but low global choice values of the street and road network. These areas are often found in the local centres in small neighbourhoods. Where there is space, these areas can facilitate high densities of dwellings with ground floor spaces for shops, small businesses, and services. Depending on the local circumstances, high-rise buildings can be considered as an option. As an example, the Sandviken area has many old wooden houses only 2-3 floors high. The type and style of buildings give this area a particular place character, and new buildings will have to adjust to the existing building stock in scale and style to avoid damaging the place identity of that area. Areas suitable for this kind of densification are the various local centres outside Bergen centre. Most of these small local centres are situated along the main routes leading through various urban areas. Areas located along the light rail line also belong in this category.

The strategy $\mathrm{C}$ areas have low local, but high global choice values of the street and road network. Often these areas are suffering from car traffic from the roads running through the areas. These locations are suitable for high densities of housing. Where possibilities exist to create a locally integrated street network, local shops on the ground floor can be facilitated. An example of such an area is in old industrial areas.

The strategy D areas have low local and low global choice values of the street and road network. These areas are mostly located in quiet residential areas. Where there is space to develop, high densities of only dwellings are desirable. These areas have a low degree of accessibility and are, therefore, unattractive for shop owners. Examples of these kinds of areas are found around the lakes and harbour areas.

Only four groups were used in this strategy report. It is also possible to use nine different groups where high, medium, and low values of global and local integration are combined. This would enable the application of more detailed strategies. In this case, however, being in the beginning stage of collaboration with the municipality and in a planning process where multiple NGO's, property owners, and stakeholders are involved, operating with four different categories is more practical than nine. In addition, the various densification strategies for each of the nine categories would need to be defined in a language understandable for practitioners.

At the end of the day, the conclusions of the report were not added to the strategic plan. Space syntax was still too unknown for some of the employees. Two years later, articles in the local newspaper are still criticising the municipality for a lack of an overall plan. However, there is a change going on in the Norwegian planning practice, where the aim is to move away from urban sprawl and towards dense cities with vibrant street life. Even though the report ended in a drawer for this project, space syntax will probably be used in future discussions for densification with good urban qualities.

\subsubsection{Regional Strategic Plan for North Holland, the Netherlands}

Space syntax was applied in the development of a strategic plan for the province of North Holland in the Netherlands in 2008. Egbert Stolk and Akkelies van Nes from the Faculty of Architecture, TU-Delft were asked to carry out a space syntax analyses of the road and street network for the whole province. The purpose was to use these analyses to develop the new strategic plan - entitled "National Policy Strategy for Infrastructure and Spatial Planning. Making the Netherlands competitive, accessible, liveable and safe"- as a guideline until the year 2040.

This province has a total area of $2,670 \mathrm{~km}^{2}$ and a population density of 1,000 people per sq $\mathrm{km}$. The Dutch capital city Amsterdam and the international airport are located in North Holland. Most urbanised areas are in close proximity to Amsterdam and Haarlem, known as the 'Randstad', whereas the northern part of the province is more rural. The strategic plan has the purpose of solving traffic congestion problems in the urbanised areas inside and around Amsterdam (Provincie Noord Holland 2008).

The focus of the space syntax analyses was on the accessibility to the vicinity of all 57 railway stations in the province of North Holland. The railway stations vary from larger metropolitan stations, airport stations, intermodal hub stations, and local stations with one small train station building to train stations with only a ticket machine. 
It is often believed that a railway station itself attracts economic activities such as shops and offices. However, the spatial configuration of the local street and road network in a railway station's vicinity is seldom taken into consideration (Mulders-Kusumo 2005). Some stations are easily accessible by foot or public transport, while others can only be reached by private car. The aim of the analysis was to assess how sustainable the public transport network for the whole region is in terms of accessibility on various scales. In general, two well-known methods are highly suitable for such an application-the node place value model (Bertolini 1999) and space syntax (Hillier 1996). Luca Bertolini's node place value model is based on correlating the degree of functionality and the degree of local place qualities for individual transport nodes in different places. Accordingly, a station functions well when the node value and the place value are high.

The parameters for the node values are variation of mobility types, frequency of public transport system of a hub, the accessibility of the network connected to the node, and the number of mobility means that can reach the hub. The higher the variation of mobility means, the higher the frequencies on the time tables during the day, and thus the higher the node value. The parameters for place value are dependent on the number of functions accessible in the vicinity of the node- such as offices, dwellings, or shopping - and the way the functions are connected to each other. The higher the number of functions and services within a short walking distance from a station, the higher the overall place value. Multi-functional nodes have a higher place value compared to mono-functional nodes.

Van Nes and Stolk (2012a, b) state that the precise definition of elements in the node place model is lacking and that the operationality of the method is rather weak. First, the quantification of functions for the node value and the quantification of different transport modes and frequencies are not clearly defined. Second, the weighting of the various parameters is also lacking. Currently, there is some testing going on to improve the node place model. The advantage of using the space syntax method for the assessment of all train stations and their spatial relations to their vicinity is that the quantitative aspects of the space syntax method are consistent. Moreover, by combining angular choice with high and low metric radii, the place value can be quantified. According to the theory of the natural urban transformation process, areas with high spatial integration on all scale levels in the vicinity of a railway station tend to have a high building density and a high degree of land use diversity.

Therefore, the application of space syntax angular choice analysis with metric radii and angular mean depth was applied to generate an accessibility profile for all 57 railway stations. Back in 2008, the segment integration was not yet applied in space syntax research (Fig. 7.24).

In a more detailed analysis, accessibility for each train station within a radius of $1 \mathrm{~km}$-which equals a 15 min walkwas analysed using the following space syntax measures and radii: Segment angular mean with a depth radius N, segment angular mean depth with a topological radius of 3, angular choice with a metric radius of $800 \mathrm{~m}$, and angular choice with a metric radius of $9,000 \mathrm{~m}$.

Figures 7.25 and 7.26 show the results of the various space syntax analyses of two of the 57 stations. For every station, the accessibility profile for a radius of $1 \mathrm{~km}$ from the station was analysed. As can be seen from the analyses of the Purmerend station (Fig. 7.25), the station is regionally well connected but locally poorly connected. Purmerend is a new town, and all the local streets have low values for the various local space syntax analyses. Conversely, the Amsterdam station (Fig. 7.26) has high values on all the space syntax analyses. Therefore, the local and regional accessibility is well supported by the local street network where the railway station is embedded.

From the accessibility profiles, all 57 train stations were classified into five different types:

- Type 1: Regionally and locally well connected to its vicinity

- Type 2: Regionally well connected but locally poorly connected to its vicinity

- Type 3: Regionally and locally well connected, but poor pedestrian accessibility

- Type 4: Regionally isolated, but locally well connected

- Type 5: Regionally and locally isolated. 
Fig. 7.24 Space syntax model from North Holland using the angular choice measure with a metric radius of $800 \mathrm{~m}$

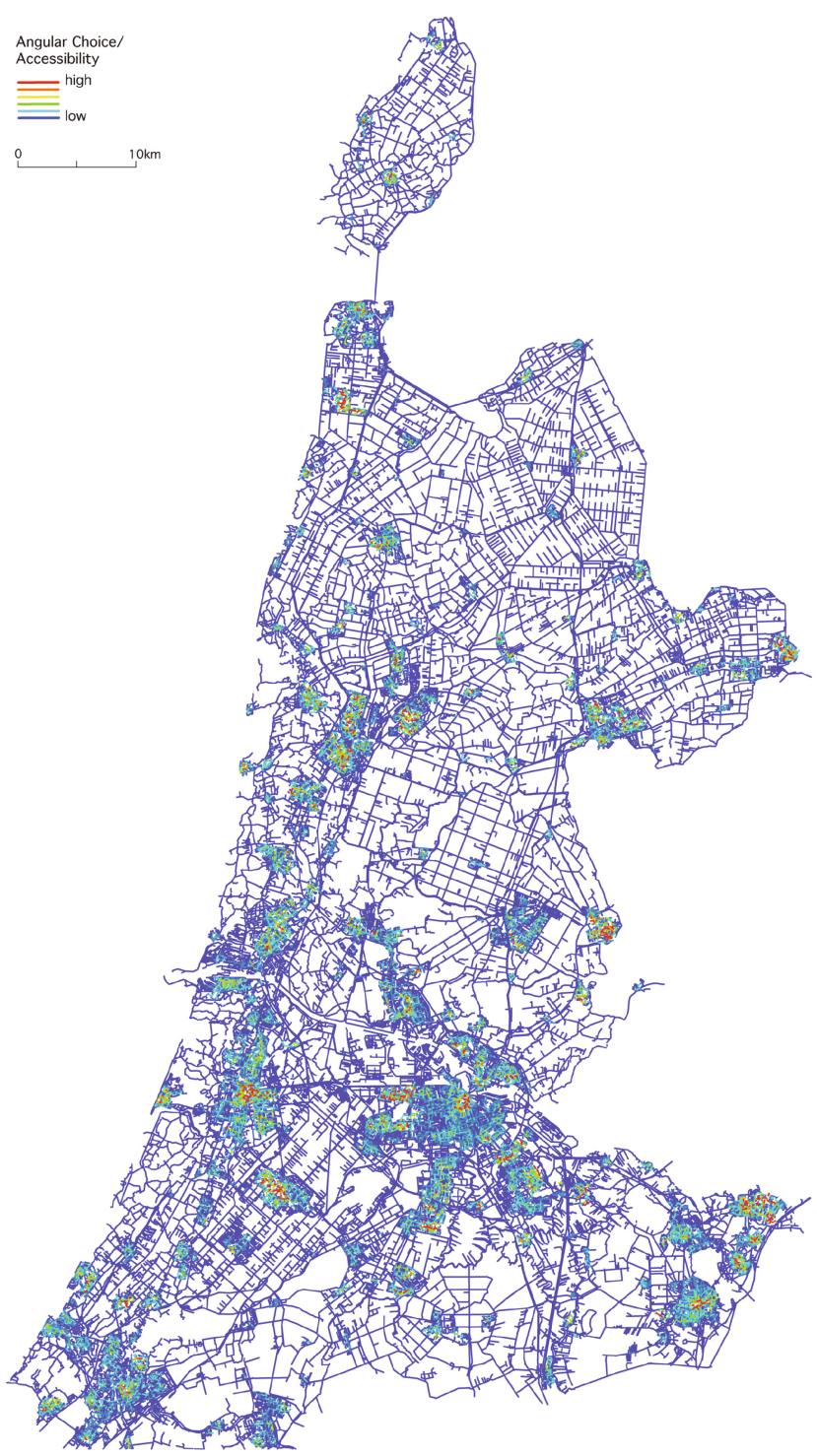

Figure 7.27 shows all five types of railway stations plotted on a map, and based on the type of accessibility profile of the railway station improvement strategies were proposed with regard to new housing areas and local accessibility to railway stations. A recommendation for facilitating new housing developments in a sustainable way is to locate them within walking distance from an existing train station. For the type 1 and 2 railway stations, the goal is to enhance a locally integrated and well-connected street network for new housing developments. The strategy for the type 3 railway station is to improve pedestrian accessibility, while the strategy for the type 4 railway station is to keep the street and road network as it is, but to enhance housing densification close to the railway station. The type 5 railway station needs to have a locally well-connected integrated street network close to the station, but only if there is a need for more residential areas in the province.

In our examples, the new town of Purmerend has a type 2 railway station and thus needs improvement in walkability within its vicinity. Amsterdam central station is a type 1 railway station, where the spatial structure of the street and road network in the vicinity supports accessibility to the central station at all scale levels.

The images in Fig. 7.28 show Haarlem station as an example of a type 1 and Sandpoort Noord station as an example of a type 5 station. Type 3 represents the newly implemented railway stations in new towns or suburbs, where pedestrian accessibility within the station's vicinity is forgotten. The street and road network is integrated on a local scale, but pedestrians have to walk complex routes to access the station. The transition station (Amsterdam Sloterdijk) and the airport station (Schiphol Airport) are typical type 2 stations, and small old historic towns (e.g. Enkhuizen) often have a type 4 railway station. 
Fig. 7.25 Accessibility profile for the new town of Purmurend's train station, north of Amsterdam. The train station is locally poorly connected but regionally well connected
Fig. 7.26 Accessibility profile for the Amsterdam train station. The train station is locally well connected and regionally well connected

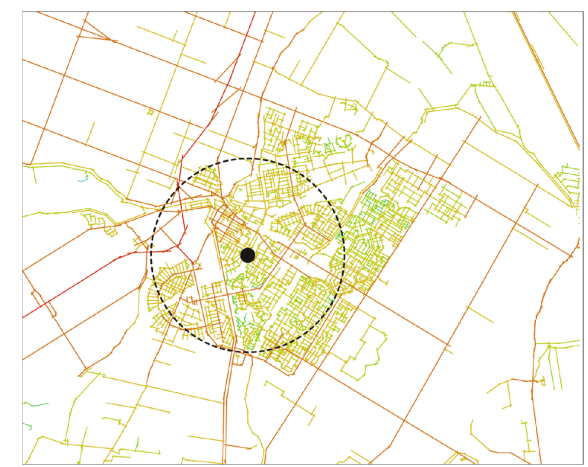

Railway station with high regional to-movement potentials (global segment integration)

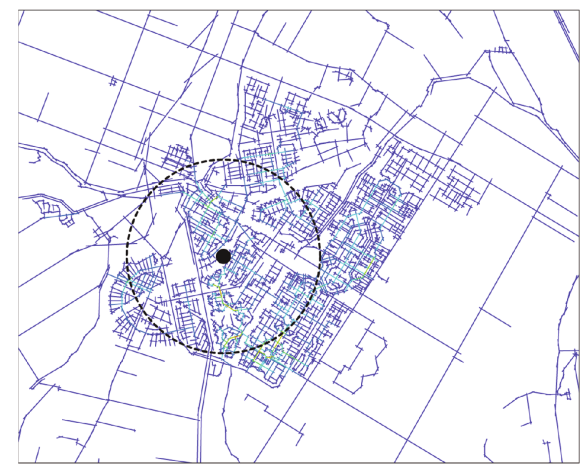

The railway station is not accessible for the pedestrian through-movement routes (choice, radius 800 meter)

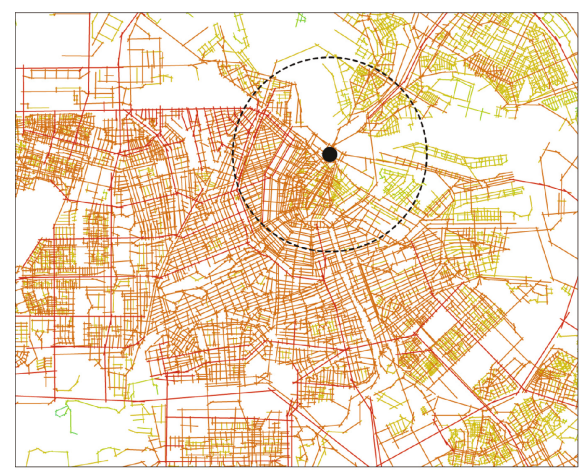

Railway station with high regional to-movement potentials (global segment integration)

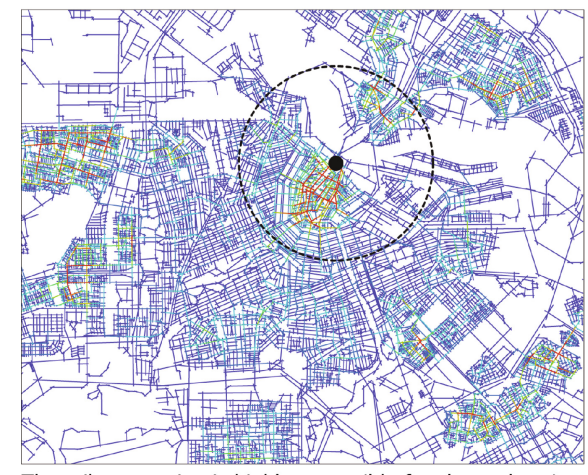

The railway station is highly accessible for the pedestrian through-movement routes (choice, radius 800 meter)

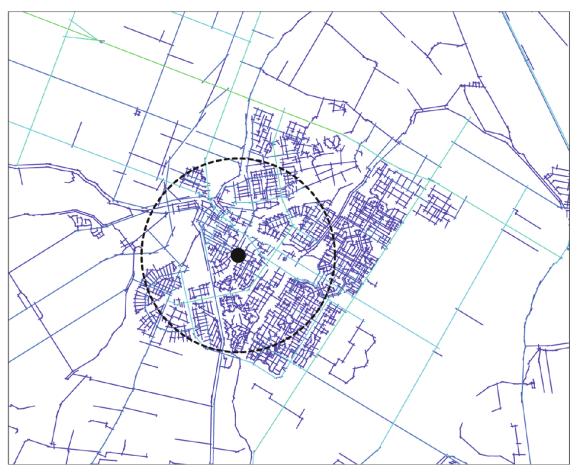

The railway station is poorly connected to the main routes (local angular analyses with three times direction change)

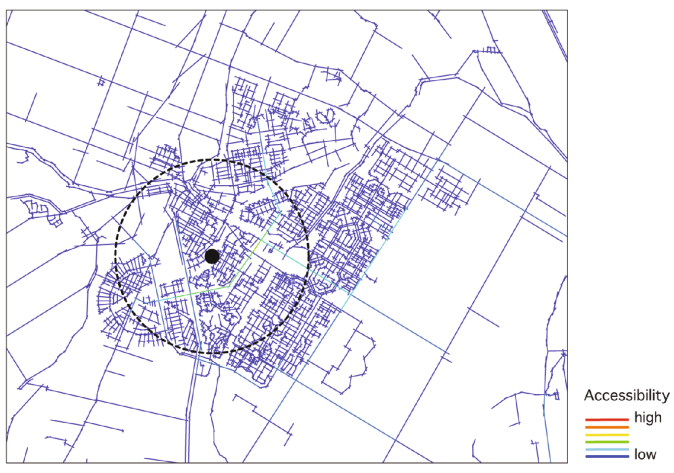

The railway station is not accessible for the car-based through-movement routes (choice, radius 9000 meter)

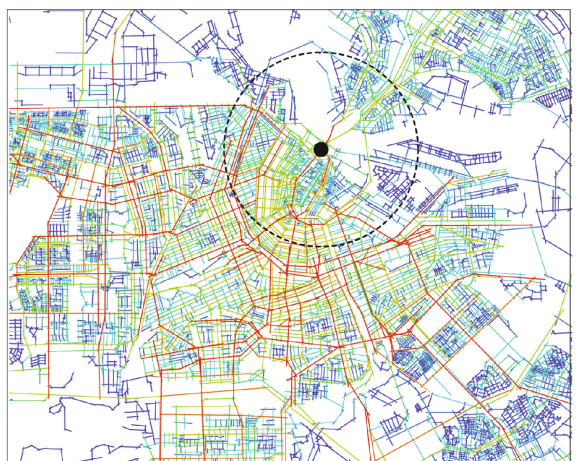

The railway station is well connected to the main routes (local angular analyses with three times direction change)

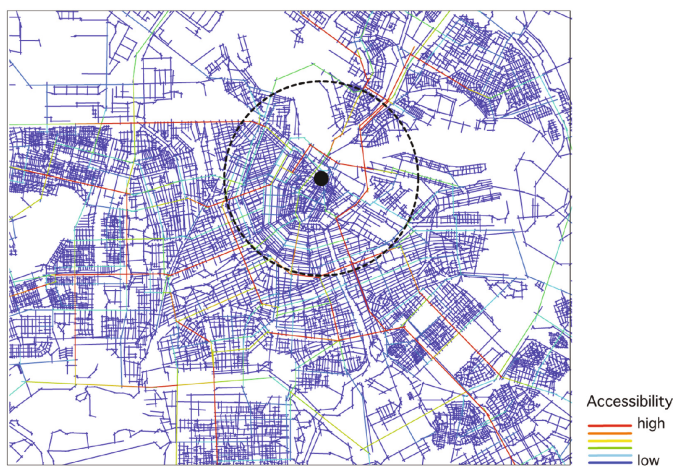

The railway station is highly accessible for the car-based through-movement routes (choice, radius 9000 meter) 
Fig. 7.27 The accessibility profile derived from space syntax analysis for North Holland
Fig. 7.28 Haarlem station, which is regionally and locally well connected (left), and

Sandpoort Noord station, a poorly connected train station with only a ticket machine (right)

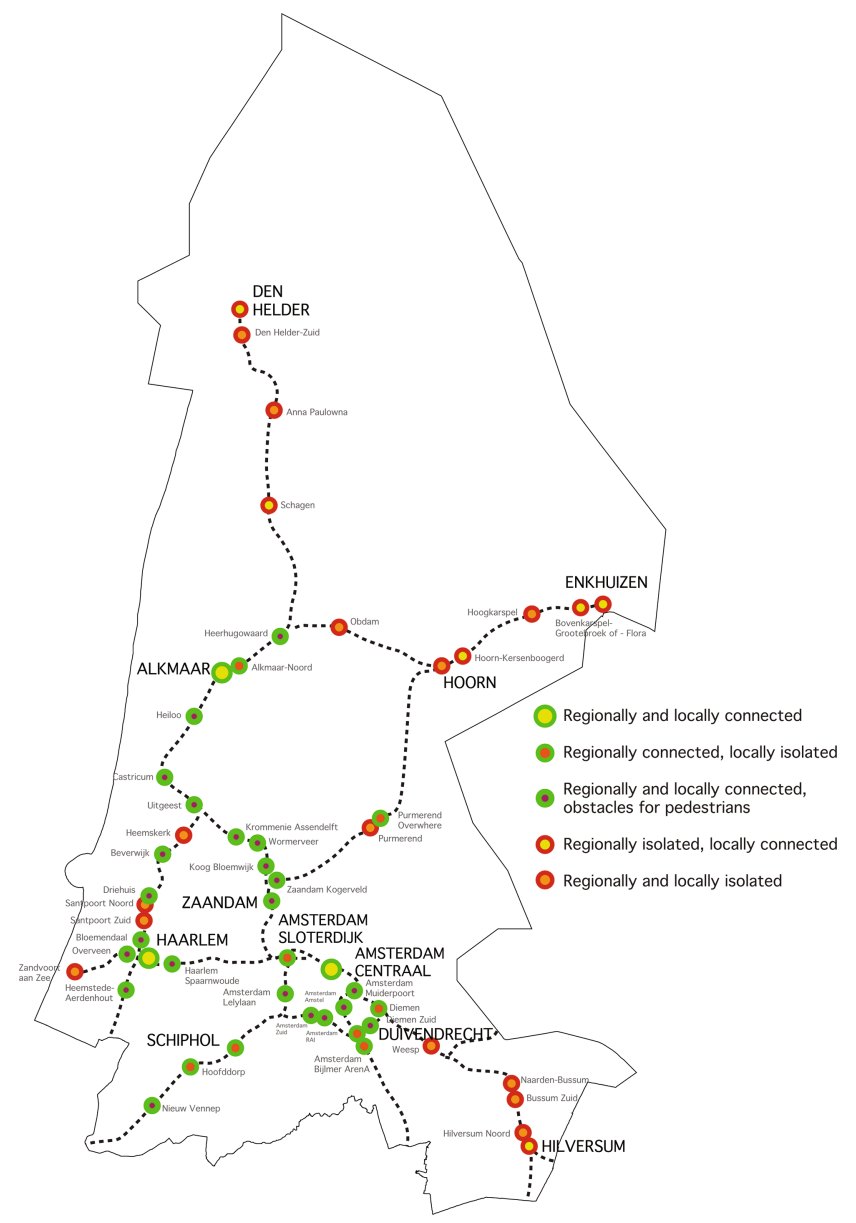

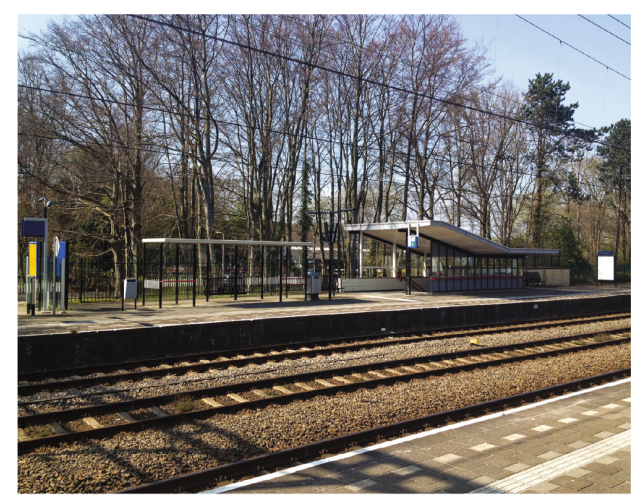

The recommendations made were partly implemented in the overall strategic plan of the province. Due to the financial crisis in the Netherlands from 2008 to 2016, the strategic plan for the province was put on hold.

In many large-scale projects, space syntax is mostly used in making diagnoses and recommendations. So far, implementation on a larger scale has not yet been carried out. The time perspective is much longer than in smaller urban renewal projects such as Trafalgar Square. However, the fact that stakeholders have started to show interest in the use of space syntax is at least a first step towards implementation. 


\subsection{Conclusion}

Applying space syntax in urban planning and design has some pitfalls to be aware of, and there is often little awareness of space syntax's theoretical and methodological limitations. Moreover, how space syntax is applied in a project depends on the problem under scrutiny. Not all types of problems can be analysed and interpreted by applying space syntax. For example, issues related to place identity, built form, and meaning cannot be interpreted using space syntax analysis. Space syntax is often applied in practice with the applicant having superficial knowledge about its theory and method, and it is then wrongly applied due to the lack of knowledge and skills. Also, a lack of awareness of its limitations or possibilities often contributes to an incorrect interpretation of space syntax results. The most common misapplications and fallacies are as follows:

\section{(1) Application of the wrong radius/radii}

The use of the wrong radius /radii can give misleading recommendations. Therefore, it is important to check the spatial analyses with various radii up to the socio-economic data in the baseline study. The radius that corresponds with the existing situation is the one you have to use for testing out the various improvement strategies.

\section{(2) Resolution of the axial map}

The resolution of the axial and segment map depends on the scale level of the investigations. Upgrading urban squares requires a higher axial map resolution than regional strategic plans because every pedestrian path needs to be represented carefully in the urban squares projects. If no axial map of the whole city exists, drawing an axial map of the neighbourhood can be sufficient for small-scale urban projects. However, sometimes one new connection can affect the whole city, for example, the Millennium Bridge in London.

(3) Combination of space syntax analysis with other types of analyses

Often the knowledge of how to combine space syntax analyses with other types of analyses is lacking. Therefore, knowledge and skills for each applied method are essential. In this context, using GIS as a platform in combination with the results of the various methods needs to be done with care.

(4) Transfer of space syntax results to planning and design guidelines

Applying research results to practical planning and design guidelines is still a young field. Often, knowledge on how to translate space syntax analysis results to, for example, design guidelines and other generic rules are missing.

\section{(5) Space syntax as a 'Do-It-Yourself' approach}

Space syntax analyses are often perceived as a colourful analytical add-on in reports, without any knowledge on how to unlock their potential. This is followed by the assumption that applying space syntax does not require theoretical and methodological knowledge. The Do-It-Yourself approach is quite common, but this leads to shallow and misinterpreted space syntax results.

\section{(6) Context dependency}

Often, there is a lack of awareness that context-dependent issues such as built form and meaning cannot be analysed or 'predicted' with space syntax.

What space syntax can predict is the impact on pedestrian flow rates and the location of economic-related activities. In the longer term, space syntax can also predict property prices and rental values on the real estate market and the potentials for densification.

Therefore, training in how to use the space syntax method is recommended before applying space syntax in urban planning and design practice. Before using space syntax in urban design and planning, always analyse the present context (the baseline study) before experimenting with various alternative improvement proposals. 
Interesting future work will be post evaluations of constructed projects where space syntax was applied in the consultation and design development phase. This will give new knowledge about the degree of the 'predictive power' of space syntax. This kind of evidence is essential to not only understand the degree of usefulness of space syntax in urban consultancy, but also to develop the space syntax method further.

\subsection{Exercises}

For the exercises, please use the software. Depthmap software and the "Depthmap manual for dummies" can be downloaded from www.spacesyntax.net and www.github.com.

\section{Exercise 1}

Use Google Maps to choose a deprived or new town neighbourhood. Imagine that the municipality wants to revitalise this area into a vibrant neighbourhood with street life. What would you advise? Develop two or three urban design options. Analyse the existing situation and your urban design options. You can choose from the space syntax pallet the analysis methods you find the most suitable for carrying out a spatial diagnosis and option testing. Explain your choices and interpret the space syntax results.

\section{Exercise 2}

Use Google Maps to download an orthogonal satellite image of the Harebakken area in Norway. Harebakken is a shopping centre in Arendal municipality and is located at the junction of the E18 highway and the local main road 410 that runs towards Arendal centre. The spatial layout of this area contributes to car-based accessibility and private car dependency. The level of walkability is very low. Harebakken is a development that is in contrast with the national Norwegian policies. Norwegian policies aim for densification of existing urban areas, while at the same time increasing active transportation such as walking and decreasing private car dependency. Develop strategies and urban design suggestions for what can be done to upgrade this area in line with Norwegian policies. Also, consider the local centre of Arendal in close proximity. What might a multi-functional local centre with vibrant street life and a high degree of walkability look like? How can it add to the existing historic core of the town Arendal without detracting from the walking potential (Fig. 7.29)?

Fig. 7.29 The Harebakken shopping centre in Arendal, Norway

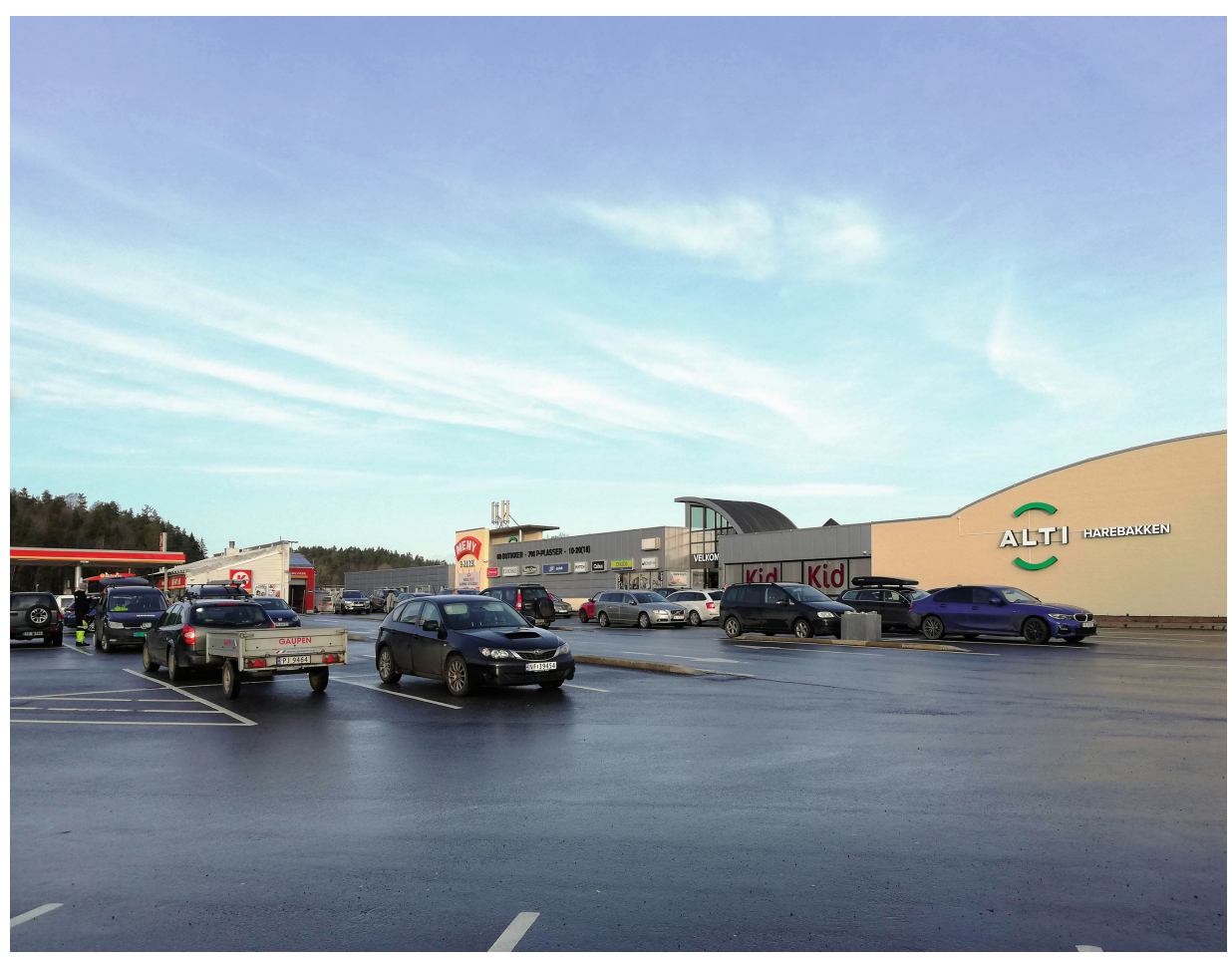




\section{Exercise 3}

Choose in Google Maps a neighbourhood you know is not functioning well. Make a diagnosis using space syntax. Use the master planning and safe neighbourhood principles to describe and explain the problems of this neighbourhood. Explain how you would assess human behaviour and the socio-economic performance of the neighbourhood. Develop an urban design proposal. In the next step, analyse on a micro-level your urban design intervention with space syntax. Describe the results of your analyses.

\subsection{Answers}

\section{Exercise 2}

The advice here is to plan a new neighbourhood around the shopping mall with a well-connected street network, balanced streets, and with buildings with doors and windows faced towards streets on the ground floor level.

\section{References}

Bertolini, L. 1999. Spatial development patterns and public transport: The application of an analytical model in the Netherlands. Planning Practice and Research 14 (2): 199-210.

De Koning, R.E., A. van Nes, Y. Ye, and H.J. Roald. 2017. Strategies for integrated densification with urban qualities. Combining space syntax with building density, land usage, public transport and property rights in Bergen city. In Proceedings of the 11th international space syntax symposium, ed. T. Heitor, M. Serra, J.P. Silva, M.B. Carreira, L.C. Da Silva, and E. Bazaraite. Lisbon: University of Lisbon.

De Koning R.E., A. Van Nes, and H.J. Roald. 2020. A scientific approach to the densification debate in Bergen centre in Norway. Sustainability, 12(21): 9178. https://doi.org/10.3390/su12219178

Dursum, P. 2007. Space syntax in architectural design. In Proceedings space syntax. 6th international symposium, ed. A.S. Kubat. Istanbul.

Hillier, B. 1996. Space is the machine: A configurational theory of architecture. Cambridge, UK: Cambridge University Press.

Hillier, B., A. Penn, and J. Hanson et al. 1993. Natural movement: Or, configuration and attraction in urban pedestrian movement. Environment and Planning B: Planning and Design 20: 29-66.

Hillier, B., A. Penn, D. Banister, and J. Xu. 1998. Configurational modelling of urban movement network. Environment and Planning B: Planning and Design 25: 59-84.

Karimi, K. 2009. The building in the urban fabric - Space syntax in practice. Presentation held at the thematic seminar A2. 7th international space syntax symposium. KTH. Stockholm.

Karimi, K. 2012. A configurational approach to analytical urban design: 'Space syntax' methodology. Urban Design International 12 (4): $297-$ 318.

Mulders-Kusumo, C. 2005. Is a railway station a 'central' urban place? Spatial configuration study of retail distribution pattern around railway stations. In Proceedings space syntax. 5th international symposium, ed. A. van Nes. Delft.

Rueb, L., and van Nes. 2009. Spatial behaviour in Dutch dwelling areas. How housing layouts affects its users' behaviour. In Proceedings 7 th international space syntax symposium, ed. D. Koch, L. Markus, and J. Steen. Stockholm.

Rønneberg Nordhov, N.A., P. Weebe Ritland, A. Larsen, and A. van Nes. 2019. The role of building entrances towards streets and the perception of safety in six neighbourhoods in Bergen. In Proceedings of the 12th international space syntax symposium, ed. S. Qiang et al. Beijing: Beijing Jiao Tong University.

Seamon, D. 1994. The life of the place. Nordisk Arkitekturforskning 1: 35-48.

Stonor, Tim. 2011. Space Syntax Ltd. London. https://timstonor.wordpress.com/2011/04/03/lincoln-lecture/.

Spacescape. 2013. Stockholm stads utbyggnadspotential. En analys av 100 och översiktsplanens stadsutvecklingsstrategier. http://www. spacescape.se/wp-content/uploads/2015/05/projektrapport_bostadspotential_130404.pdf.

Van Nes, A. 2007. Centrality and economic development in the Rijnland region. Social and spatial concepts of centrality. In Proceedings space syntax. 6th international symposium, ed. A.S. Kubat. Istanbul.

Van Nes, A., and M. López. 2010. Macro and micro scale spatial variables and the distribution of residential burglaries and theft from cars: An investigation of space and crime in the Dutch cities of Alkmaar and Gouda. Journal of Space Syntax (2).

Van Nes, A., and E.H. Stolk. 2012a. The socio-economic impact of various road alternatives in town centres. The application of space syntax in road planning in Rijnland and Tønsberg. Paper presented at the 26th AESOP Annual Congress. Istanbul.

Van Nes, A., and E.H. Stolk. 2012b. Degrees of sustainable location of railway stations: Integrating space syntax and node place value model on railway stations in the province Noord-Holland's strategic plan for 2010-2040. In Proceedings space syntax. 8th international symposium, ed. M. Greene. Santiago, Chile: Pontificia Universidad Católica de Chile.

Van Nes, A., and M. López. 2013. Spatial-socio classification of deprived neighbourhoods in the Netherlands. In Proceedings space syntax. 9th international symposium, ed. Young Ook Kim, Hoon Tae Park, and Kyung Wook Seo. Sejong University Press, Seoul, Korea.

Yamu, C., A. van Nes, and C. Garau. 2021. Bill Hillier's legacy: space syntax_a synopsis of basic concepts, measures, and empirical application. Sustainability, 13(6), 3394. https://doi.org/10.3390/su13063394

Ye, Y., and A. van Nes. 2014. Quantitative tools in urban morphology: Combining space syntax, spacematrix and mixed-use index in a GIS framework. Urban Morphology 18 (2): 97-118. 


\section{Further Readings}

Carmona, M., T. Heath, T. Oc, and S. Tiesdel. 2012. Public places-Urban spaces. Routledge.

Gehl, J. 1987. Life between buildings. London: Island Press.

Hillier, B. 1996. Space is the machine: A configurational theory of architecture. Cambridge, UK: Cambridge University Press.

Hillier, B., and J. Hanson. 1984. The social logic of space. Cambridge, UK: Cambridge University Press.

Karimi, K. 2012. A configurational approach to analytical urban design: 'Space syntax' methodology. Urban Design International 12 (4): $297-$ 318.

LeGates, R.T., and F. Stout. 2011. The city reader, 5th ed. Routledge urban reader series.

Yamu, C., A. van Nes, and C. Garau. 2021. Bill Hillier's legacy: space syntax—a synopsis of basic concepts, measures, and empirical application. Sustainability, 13(6), 3394. https://doi.org/10.3390/su13063394

Open Access This chapter is distributed under the terms of the Creative Commons Attribution 4.0 International License (http://creativecommons. org/licenses/by/4.0/), which permits use, duplication, adaptation, distribution and reproduction in any medium or format, as long as you give appropriate credit to the original author(s) and the source, a link is provided to the Creative Commons license and any changes made are indicated.

The images or other third party material in this chapter are included in the work's Creative Commons license, unless indicated otherwise in the credit line; if such material is not included in the work's Creative Commons license and the respective action is not permitted by statutory regulation, users will need to obtain permission from the license holder to duplicate, adapt or reproduce the material. 